NBER WORKING PAPER SERIES

\title{
UNDERSTANDING CHANGES IN INTERNATIONAL BUSINESS CYCLE DYNAMICS
}

\author{
James H. Stock \\ Mark W.Watson \\ Working Paper 9859 \\ http://www.nber.org/papers/w9859
}

\author{
NATIONAL BUREAU OF ECONOMIC RESEARCH \\ 1050 Massachusetts Avenue \\ Cambridge, MA 02138 \\ July 2003
}

The authors thank Dick van Dijk, Brian Doyle, Graham Elliott, Jon Faust, Andrew Harvey, Siem Jan Koopman, Denise Osborn, and Lucrezia Reichlin for helpful comments and discussions. This research was funded in part by NSF grant SBR-0214131. The views expressed herein are those of the authors and not necessarily those of the National Bureau of Economic Research

(C)2003 by James H. Stock and Mark W. Watson. All rights reserved. Short sections of text not to exceed two paragraphs, may be quoted without explicit permission provided that full credit including (C) notice, is given to the source. 
Understanding Changes in International Business Cycle Dynamics

James H. Stock and Mark W. Watson

NBER Working Paper No. 9859

July 2003

JEL No. E3

\section{$\underline{\text { ABSTRACT }}$}

The volatility of economic activity in most G7 economies has moderated over the past forty years. Also, despite large increases in trade and openness, G7 business cycles have not become more synchronized. After documenting these twin facts, we interpret G7 output data using a structural VAR that separately identifies common international shocks, the domestic effects of spillovers from foreign idiosyncratic shocks, and the effects of domestic idiosyncratic shocks. This analysis suggests that, with the exception of Japan, the widespread reduction in volatility is in large part associated with a reduction in the magnitude of the common international shocks. Had the common international shocks in the 1980s and 1990s been as large as they were in the 1960s and 1970s, G7 business cycles would have been substantially more volatile and more highly synchronized than they actually were.

James H. Stock

Department of Economics

Harvard University

Littauer Center M4

Cambridge, MA 02138

and NBER

james_stock@harvard.edu
Mark W. Watson

Woodrow Wilson School

Princeton University

Princeton, NJ 08544-1013

and NBER

mwatson@princeton.edu 


\section{Introduction}

Most of the G7 economies have experienced a reduction in the volatility of output growth, and a concomitant moderation of business cycle fluctuations, in the past two decades. Table 1 presents the decadal averages and standard deviations of four-quarter growth rates of per capita GDP for each of the G7 countries for the past four decades. Germany, Italy, Japan, the UK, and the US all experienced large reductions in volatility, while France and Canada experienced smaller moderations. Over this period, international trade flows have increased substantially, financial markets in developed economies have become increasingly integrated, and continental European countries moved to a single currency. These developments raise the possibility of changes not only in the severity of international business cycles, but also in their synchronization.

There already is a large body of research on these changes, and there is a consensus concerning many of the basic facts. As initially pointed out by Kim and Nelson (1999) and McConnell and Perez-Quiros (2000), there has been a substantial moderation in output fluctuations in the US, with these and most other authors suggesting that this moderation is well modeled as a single break in the mid 1980s. Some of the proposed explanations of this moderation, such as changes in monetary policy and adoption of new inventory management methods, are domestic in origin, while others, such as smaller international shocks or stabilizing effects of trade, have international roots; for further discussion and references see Blanchard and Simon (2001) and Stock and Watson (2002a).

Although the moderation of volatility is also evident in international data, when modeled as a single break the reductions generally are neither concurrent nor of similar magnitudes (e.g. Dalsgaard, Elmeskov and Park (2002), Del Negro and Otrok (2003), Doyle and Faust (2002), van Dijk, Osborn, and Sensier (2002), Fritsche and Kouzine (2003), Mills and Wang (2000), Simon (2001)). Moreover, existing research suggests

little tendency towards increasing international synchronization of cyclical fluctuations (Doyle and Faust (2002a, 2002b), Heathcoate and Perri (2002), Kose, Prasad, and Terrones (2003)). Instead, there appears to have been an emergence of at least one cyclically coherent group, the major countries in the Euro-zone (Artis, Kontelemis, and 
Osborn (1997), Artis and Zhang (1997, 1999), Carvalho and Harvey (2002), Helbling and Bayoumi (2003), Dalsgaard, Elmeskov and Park (2002), Del Negro and Otrok (2003), Luginbuhl and Koopman (2003)), and possibly a second, English-speaking group, consisting of Canada, the UK, and the US (Helbling and Bayoumi (2003)).

This paper has two specific objectives. The first is to provide a concise summary of the empirical facts about the moderation in output volatility, changes in persistence, and changes in cyclical comovements for the G7 countries. One conclusion is that the single-break model of variance reduction, which fits the US well, does not adequately describe the international patterns of moderation. In addition, we provide further evidence of the emergence of two cyclical groups, the Euro-zone and English-speaking groups.

Our second objective is to provide quantitative estimates of the sources of these changes: are they domestic or international in origin, and do they reflect changes in the magnitudes of structural shocks or, rather, changes in the response of the economies to those shocks? To obtain these estimates, we use a so-called factor-structural vector autoregression (FSVAR), specified in terms of the growth rates of quarterly GDP in the G7 countries. This FSVAR is a conventional structural VAR, where the identifying restrictions come from imposing an unobserved-component factor structure on the VAR innovations. The idiosyncratic shocks are allowed to affect future output in other countries, so this FSVAR makes it possible to quantify both the direct effect of common international shocks and the indirect effect of spillovers from the domestic shocks in one country to its trading partners. The FSVAR is overidentified, and tests of the overidentifying restrictions suggest that the $\mathrm{G} 7$ output data are well described as being driven by two common international shocks, plus seven country-specific shocks. This FSVAR makes it possible to address various counterfactual questions, and (for example) facilitates estimating the extent to which the moderation in volatility is a result of smaller common international shocks, is domestic in origin, or is the result of a moderation in the US which spills over into the other G7 countries.

The data and the two methods we use to remove trends and to isolate business cycle components are briefly described in Section 2. Section 3 summarizes the empirical facts about changes in volatility and persistence for the individual G7 output data, and 
Section 4 summarizes the changes in international correlations. The FSVAR is described, and its overidentifying restrictions are tested, in Section 5. Empirical results and counterfactual calculations based on the FSVAR are presented in Section 6. Section 7 concludes.

\section{Data and Filters}

The data are quarterly per capita real GDP for the G7 countries (Canada, France, Germany, Italy, Japan, UK, and US), covering 1960:1 - 2002:4. Data sources are summarized in Table A-1.

The long-term growth rate of GDP is not constant for some of these countries, especially Germany, Japan, and Italy. The focus of this paper is fluctuations at yearly through business cycle horizons, not the determinants of early postwar growth in Germany, Japan, and Italy. Because a low-frequency drift can introduce bias into certain statistics, such as cross-country correlations computed over large subsamples, we adopt two alternative methods for eliminating this low-frequency component.

The first method is to detrend the growth rate of GDP using an unobserved components model with a time-varying drift. Let $y_{t}=400 \Delta \ln \left(G D P_{t}\right)$ be the quarterly growth of GDP at an annual rate. We adopt an unobserved components specification which represents $y_{t}$ as the sum of two terms, a slowly evolving mean growth rate and a stationary component:

$$
y_{t}=\mu_{t}+u_{t}, \text { where } \mu_{t}=\mu_{t-1}+\eta_{t}
$$

and $a(\mathrm{~L}) u_{t}=\varepsilon_{t}$, where $\mathrm{L}$ is the lag operator and $\varepsilon_{t}$ and $\eta_{t}$ are serially and mutually uncorrelated mean zero disturbances. The Kalman smoother can be used to estimate the local mean, $\mu_{t}$, and the residual. The detrended GDP growth rate is the residual, that is, the Kalman smoother estimate of $u_{t}$.

Implementing this detrending procedure requires a value of ratio $\sigma_{\eta}^{2} / s_{u u}(0)$, where $s_{u u}(0)$ is the spectral density of $u_{t}$ at frequency zero. When $\sigma_{\eta}^{2} / s_{u u}(0)$, is small, as it is 
likely to be in this application, the maximum likelihood estimator of $\sigma_{\eta}^{2} / s_{u u}(0)$ has the "pileup" problem of having asymptotic point mass at zero even if its true value is nonzero but small, so we estimate $\sigma_{\eta}^{2} / s_{u u}(0)$ on a country-by-country basis using the medianunbiased estimator of Stock and Watson (1998), and use this country-specific estimate to detrend GDP growth. ${ }^{1}$

The four-quarter growth rates of GDP in the seven countries are plotted in Figure 1. Figure 2 plots the detrended four-quarter growth rates, that is, the rolling four-quarter average of the detrended quarterly growth rates. Comparison of Figures 1 and 2 reveals that the detrending procedure eliminates the local mean of each series, but otherwise leaves the series essentially unchanged. Figure 2 also shows the simple average of the four-quarter growth rates for the G7 countries. Evidently many of these countries have episodes of considerable comovement, or synchronization, with aggregate G7 fluctuations.

The second filtering method we use is the Baxter-King (1999) band-pass (BP) filter, with 8 leads and lags and a pass-band of 6 to 32 quarters, applied to $\log \left(G D P_{t}\right)$. Band-pass-filtered GDP for each country are plotted in Figure 3, along with the average of the BP-filtered G7 GDP. Evidently BP-filtered GDP, like four-quarter growth, has periods of considerable international synchronization in business cycles. Notably, at the level of detail of Figures 2 and 3, the period of greatest synchronization appears to be the 1970s, and there is no readily apparent trend towards increased synchronization.

\section{Changes in Volatility and Persistence}

This section presents statistics summarizing the changes in the volatility of GDP and the persistence of innovations to GDP in the G7 countries.

\subsection{Volatility}

\footnotetext{
${ }^{1}$ The median-unbiased estimators of $\left[T^{2} \sigma_{\eta}^{2} / s_{u u}(0)\right]^{1 / 2}$ were computed by on inverting the point optimal invariant statistic with local parameter 7; see Stock and Watson (1998) for
} 
As discussed in the introduction, there has been a substantial moderation in volatility in the post-1983 period, relative to the pre-1983 period. To get more detail on this moderation, we estimate the time path of the instantaneous variance of GDP using a nonGaussian smoother based on a stochastic volatility model with heavy tails and timevarying autoregressive coefficients. Let $y_{t}$ be the quarterly GDP growth at an annual rate. The stochastic volatility model is,

$$
y_{t}=\alpha_{0 t}+\sum_{j=1}^{p} \alpha_{j t} y_{t-j}+\sigma_{t} \varepsilon_{t}, \text { where } \alpha_{j t}=\alpha_{j t-1}+c \eta_{j t} \text { and } \ln \sigma_{t}^{2}=\ln \sigma_{t-1}^{2}+\zeta_{t},(2)
$$

where $\varepsilon_{t}, \eta_{1 t}, \ldots, \eta_{p t}$ are i.i.d. $N(0,1)$ and where $\zeta_{t}$ is distributed independently of the other shocks. To allow for large jumps in the instantaneous innovation variance, $\zeta_{t}$ is drawn from a mixture-of-normals distribution. The time-varying parameters were estimated by Markov Chain Monte Carlo methods. Given $\alpha_{0 t}, \ldots, \alpha_{p t}$, and $\sigma_{t}^{2}$, it is possible to compute the instantaneous standard deviations of GDP growth, of four-quarter GDP growth, and of BP-filtered GDP for an idealized BP filter. For additional details, see Stock and Watson (2002a, Appendix A).

The resulting estimated instantaneous standard deviation of 4-quarter GDP growth is plotted in Figure 4. Different countries exhibit quite different paths of instantaneous standard deviations. In the US, there was a sharp moderation in the mid1980s, while in the UK volatility declined in the late 1970s. Germany experienced a large but gradual decline in volatility, while volatility moderated in Japan but has increased recently. Figure 5 plots the implied instantaneous standard deviation of BPfiltered GDP. Comparison of Figures 4 and 5 shows nearly identical patterns for fourquarter growth rates and BP-filtered GDP.

Formal tests for breaks in the conditional mean (that is, the autoregressive lag coefficients) and the conditional variance (that is, the autoregressive innovation variance)

details. The estimates are: Canada, 6.4; France, 9.3; Germany, 3.3; Italy, 8.9; Japan, 6.2; $\mathrm{UK}, 0.0$; and US, 3.1. 
of GDP growth are reported in Table 2. ${ }^{2}$ The hypothesis of constant parameters is tested using the Wald version of the Quandt likelihood ratio (QLR) statistic, evaluated over the central $70 \%$ of the sample; the test of a constant conditional variance allows for the possibility of a break in the conditional mean at an unknown date that differs from the break date for the conditional variance. The break date and its $67 \%$ confidence interval are reported when the QLR statistic rejects at the 5\% significance level. The final block of Table 2 tests an alternative specification in which the innovation variance is modeled as a linear function of time with a discrete jump at an unknown break date, thereby nesting the single-break and linear time trend specifications.

The results in Table 2 indicate widespread instability in both the conditional mean and the conditional variance of these autoregressive models for GDP: in five of the seven countries, the hypothesis of a constant conditional mean is rejected at the $5 \%$ level, and in all countries but Japan the hypothesis of a constant conditional variance is rejected. For the US, the results in the final block suggest that the break model is preferred to a linear time trend: in the nested specification, the break is significant but the time trend is not. This finding does not generalize to the other countries, however. For example, for Germany neither the trend term nor the break term are individually significant in the nested specification. This finding does not imply that the variance for Germany was constant, for the test in panel B rejects the no-break specification at the $1 \%$ level and the estimated instantaneous variances in Figure 3 indicates a substantial reduction in volatility over this period; rather, the nonrejections for Germany and Japan - and the significance of both terms for the UK - suggests that neither the single-break nor the linear-decline model provides a good summary of the changing volatility for these countries. Although the nested tests in the final block of Table 2 point towards the trend model for Canada and Italy, the estimates in Figures 5 and 6 look more like a series of plateaus than a linear trend. Taken together, we interpret this all as evidence that the pattern of the change in GDP volatility for most G7 countries is more complex than the single-break model that describes the U.S.

\footnotetext{
${ }^{2}$ Raw (i.e. not detrended) GDP growth rates are used in the tests in Table 2 to ensure that currently available theory can be used for the null distribution of the break tests (Andrews (1991)) and the distribution of the break date estimators (Bai (1997)).
} 


\subsection{Persistence and Size of Univariate Shocks}

Another way to look at the changing autocovariances of GDP growth in these countries is to examine changes in the variance of the AR innovation and in the sum of the AR coefficients, which measures the persistence of a shock to GDP growth. Changes in the variance of GDP growth imply that that its spectrum has changed; an increase in the sum of the AR coefficients implies an increase in the relative mass at frequency zero, while a change in the innovation variance implies a shift in the level (but not necessarily the shape) of the spectrum.

Table 3 presents the sum of the coefficients and the one-step ahead forecast standard error for univariate AR models of detrended GDP growth. The sum measures the persistence of an innovation to GDP, and by this measure GDP innovations have become substantially more persistent for Canada, France, and the UK. Persistence has increased slightly for the US and Italy, while it has declined for Germany and Japan. For all countries except Japan, the magnitude of the GDP innovations, as measured by the standard error of the regression, has decreased substantially: one-quarter ahead forecasts based on univariate autoregressions have become more accurate for the G7 countries.

Figure 6 presents estimated time paths for the sum of coefficients and AR error variance. These estimates are computed using a rolling fourth-order autoregression, where the autoregression is estimated by weighted least squares with two-sided exponential weighting, with a quarterly discount factor of .97; the date plotted in the figure corresponds to the central observation with the greatest weight. ${ }^{3}$ These figures are consistent with the two-sample evidence in Table 3. In all countries, the innovation variance fell substantially, although it increased again during the 1990s in Japan. In Canada, France, and the UK, persistence has increased substantially, while persistence has been roughly constant for the US. The timing of these changes differs across

\footnotetext{
${ }^{3}$ That is, the estimate plotted at date $s$ is based on weighted least squares estimation of the AR using all observations, with the observation at date $t$ receiving weight $.97^{|s-t|}$. Similar results are obtained using the nonGaussian smoother estimates based on (2). The two-sided exponential weighting scheme is used here for comparability with the twosided VAR estimates reported in Sections 4 and 6.
} 
countries, a result consistent with variations in the patterns of declining variances in Figures 4 and 5.

\section{Changes in Synchronization}

This section reports various measures of time-varying international comovements of GDP. To facilitate comparisons with the analysis of Sections 5 and 6 using the FSVAR, these measures are estimated using a reduced form seven-country VAR. The section begins by describing the reduced form VAR, then turns to the measures of timevarying correlations.

\subsection{Reduced Form VAR}

A conventional $\operatorname{VAR}(p)$ with all seven countries would have $7 p$ coefficients in each equation, where $p$ is the number of lags. With the short quarterly data set at hand, this many coefficients would induce considerable sampling uncertainty even with small values of $p$. One solution to this dimensionality problem is to consider VARs specified in terms of subsets of countries, as is done by Doyle and Faust (2002b), but this limits the international spillovers and common shocks that can be studied in a single model. Another solution is to specify a model for all seven countries but to impose additional restrictions on the VAR coefficients, as is done in many papers in this literature, for example Helg et. al. (1995). We take this latter route and consider two such sets of restrictions.

For the main results, the restriction we use is for lagged foreign GDP growth to enter with a different number of lags than domestic GDP growth. Specifically, let $Y_{t}$ be the vector of detrended quarterly GDP growth rates. The reduced form VAR is

$$
Y_{t}=A(\mathrm{~L}) Y_{t-1}+v_{t}, \text { where } E v_{t} v_{t}^{\prime}=\Sigma
$$

where the diagonal elements of the matrix lag polynomial $A(\mathrm{~L})$ have degree $p_{1}$ and the off-diagonal elements have degree $p_{2}$. Denote the resulting $\operatorname{VAR}$ by $\operatorname{VAR}\left(p_{1}, p_{2}\right)$. The $\mathrm{AIC}$ and BIC, computed for the two subsamples, point to a $\operatorname{VAR}(4,1)$ specification. 
The second restriction we considered further restricts the coefficients on the lags of foreign GDP to be proportional to their trade shares, an approach taken by Elliott and Fatás (1997) and Norrbin and Schlagenhauf (1996). Results from that VAR are reported as part of the sensitivity analysis in Section 6.

The second moments of interest in this paper can all be computed directly from estimates of the VAR parameters in (3). The spectral density matrix of quarterly growth $Y_{t}$ is $S_{Y Y}(\omega)=A\left(\mathrm{e}^{i \omega}\right) \Sigma A\left(\mathrm{e}^{-i \omega}\right)^{\prime} / 2 \pi$. The implied spectral density matrix of four-quarter GDP growth is $\left\|1+\mathrm{e}^{i \omega}+\mathrm{e}^{2 i \omega}+\mathrm{e}^{3 i \omega}\right\|^{2} S_{Y Y}(\omega)=\left\{s_{i j}^{(4)}(\omega)\right\}$, so that $s_{i j}^{(4)}(\omega)$ is the crossspectrum (spectrum when $i=j$ ) between four-quarter GDP growth in country $i$ and country $j$ at frequency $\omega$. The implied spectral density matrix of BP-filtered GDP growth is $\left\|b\left(\mathrm{e}^{i \omega}\right) /\left(1-\mathrm{e}^{i \omega}\right)\right\|^{2} S_{Y Y}(\omega)$, where $\|z\|^{2}$ is the squared norm of the possibly complex variable $z$ and $b$ is the idealized BP filter so that $\left\|b\left(\mathrm{e}^{i \omega}\right)\right\|^{2}=1$ for $\omega_{0} \leq \omega \leq \omega_{1}$, where the frequencies $\omega_{0}$ and $\omega_{1}$ respectively correspond to periodicities of 32 and 6 quarters, and $\left\|b\left(\mathrm{e}^{i \omega}\right)\right\|^{2}=0$ otherwise. Thus, for example, the contemporaneous correlation $\rho_{i j}^{(4)}$ between four-quarter growth rates in countries $i$ and $j$ is

$$
\rho_{i j}^{(4)}=\frac{\int_{-\pi}^{\pi} s_{i j}^{(4)}(\omega) d \omega}{\left(\int_{-\pi}^{\pi} s_{i i}^{(4)}(\omega) d \omega\right)^{1 / 2}\left(\int_{-\pi}^{\pi} s_{j j}^{(4)}(\omega) d \omega\right)^{1 / 2}}
$$

Various second moments were computed both for the two subsamples and for rolling estimates of the VAR parameters. The rolling VAR parameters were estimated by weighted least squares using the two-sided exponential weighting scheme described in Section 3 for the rolling ARs.

\subsection{International Synchronization}

Table 4 presents various measures of international output comovements. Panels A and B tabulate the correlation of four-quarter GDP growth rates across countries, first using the raw data then based on the estimated model. The average absolute difference of 
these estimated correlations is .04 in the first subsample and .10 in the second subsample, indicating that that the reduced form $\operatorname{VAR}(4,1)$ captures most of the business cycle comovements of these series; the biggest exception is that the $\operatorname{VAR}(4,1)$ estimated correlation considerably exceeds the sample correlation between US and French fourquarter GDP growth in the second period. Panel C of Table 4 presents the correlations among BP filtered GDP estimated using the reduced form $\operatorname{VAR}(4,1)$; the entries in Panel $\mathrm{C}$ and correlations estimated directly from BP-filtered data (not tabulated) differ by an absolute average of .08 in the both the first and second periods.

Rolling correlations between own-country BP-filtered GDP and US and German BP-filtered GDP, based on the reduced-form VAR(4,1), are plotted in Figure 7; like the other plots of rolling estimates, the plotted date corresponds to the center of the rolling window, the date with the greatest weight in the rolling exponential weighting scheme.

Three aspects of Table 4 and Figure 7 bear emphasis. First, as emphasized by Doyle and Faust (2002a, 2002b), Heathcoate and Perri (2002), and Kose, Prasad, and Terrones (2003), there is no overall tendency towards closer international synchronization over this period: depending on the correlation measure used, the average cross-country correlation either is unchanged between the two subsamples or drops slightly.

Second, there nevertheless appears to have been substantial shifts in comovements among the G7 economies, but these shifts are more towards the emergence and evolution of Euro-zone and English-speaking regional groups. Based on the correlations in Table 4(a), during the first subsample the average correlation within the two groups was .50 (continental Europe) and .50 (English-speaking), and the average cross-group correlation was .38. In contrast, in the second period the average correlations within the two groups rise to.65 (continental Europe) and .70 (English-speaking), while the average cross-group correlation drops to .28. A significant part of this change is the decline in the correlation between UK GDP growth and that of France and Germany, and an increase in its correlation with the North American economies. The emergence of the two regional groups, English-speaking and Euro-zone, also is evident in Figure 7 through the increasing French-German and Italian-German correlations and the increasing correlation between the UK and the US (and their decreasing correlations with Germany). 
Third, the synchronization of Japanese cycles with the rest of the G7 has been low throughout this forty-year period and recently decreased further. Based on the correlations of four-quarter GDP growth in Table 4(a), from 1960 - 1983 the average correlation between Japan and the other G7 countries fell from 0.35 during 1960 - 1983 to 0.18 during $1984-2002$.

\section{The Factor-Structural VAR model}

There are several frameworks available for developing a time series model with enough structure to permit answering the questions of interest here, such as the fraction of a country's cyclical variance that is due to international shocks and how that has changed over time. Before discussing the specific framework used in this paper, a structural VAR, it is useful to discuss the various modeling options available and to assess their strengths and weaknesses.

The basic issue to be resolved is the best way to identify a world (or G7) shock. One approach is simply to define a world shock to be the innovation in a univariate time series model of world (or G7) GDP growth. While this approach has the advantage of being easy to implement, because US output receives great weight in G7 GDP it confounds world shocks with US shocks and idiosyncratic shocks to other large economies. Suppose there were in fact no common shocks and no trade; this identification scheme would nevertheless attribute a large fraction of US fluctuations to a common shock as an arithmetic implication of its construction.

A second approach is to use a parametric dynamic factor model in which the number of shocks exceeds the number of series, and the comovements across series at all leads and lags are attributed to the common shock. This leads to an unobserved components model that can be estimated using Kalman filtering and related methods. This approach has been widely used in the international fluctuations literature; recent contributions include Kose, Otrok, and Whiteman (2001), Kose, Prasad, and Terrones (2003), Harvey and Carvalho (2002), Luginbuhl and Koopman (2003), and Monfort, Renne, Rüffer, and Vitale (2002). This framework has several advantages. In the hypothetical case of no trade and no common shocks, there would be no comovements 
and the common shock would correctly be estimated to have zero variance. This framework also captures the differences in dynamic responses of different economies to a world shock. On the other hand, because cross-dynamics are all attributed to the world shock, this approach is not well suited to identifying the separate effects of a common world shock and spillovers arising through trade: if there were in fact no world shocks but idiosyncratic shocks were transmitted through trade, the parametric dynamic factor model would incorrectly estimate a nonzero world shock. ${ }^{4}$

A third approach is to use nonparametric methods to estimate a dynamic factor model. If a large number of series have a dynamic factor structure, then the common component or the common dynamic factor can be estimated using principal components (Stock and Watson (2002b)) or dynamic principal components (Forni, Hallin, Lippi, and Reichlin (2000)). This strategy is used by Helg et. al. (1995) to extract European industry and country shocks as principal components of reduced-form VAR errors, and by Helbling and Bayoumi (2003) to estimate the importance of common factors in G7 fluctuations. Prasad and Lumsdaine (2003) also adopting this strategy, using a weighting scheme rather than principal components to extract the innovation in a single common G7 factor. In principle the principal components/nonparametric approach has the advantages of the second approach without the disadvantage of assuming that all comovements stem from the common disturbance rather than through trade spillovers; in practice, however, if this approach is based on only the G7 then individual countries are necessarily heavily weighted leading to the same problems as the first approach, in particular finding a common factor even if there is none.

A fourth approach, the one used here, is to adopt a VAR framework for the lagged effects but to identify world shocks as those that affect all countries within the same period. Thus country-specific shocks can lead to spillovers, but those spillovers are assumed to happen with at least a one-quarter lag. In practice this results in an overidentified structural VAR, in which the shocks are identified by imposing a factor

\footnotetext{
${ }^{4}$ Monfort, Renne, Rüffer, and Vitale (2002) partially address this drawback by considering, as an alternative to their main analysis, a specification with regional shocks that interact dynamically and thus allow cross-region spillovers. Going further down this route and fully relaxing the lag dynamics would lead to the FSVAR model discussed below.
} 
structure on the reduced-form errors. Examples of papers using this approach (in a regional or international context) include Altonji and Ham (1990), Norrbin and Schlagenhauf (1996), and Clark and Shin (2000). Two advantages of this approach are that no world shock is estimated if there is none, or if all cross-dynamics arise from lagged trade spillovers. A potential disadvantage of this approach is that if an international shock affects several countries only with a lag, that effect may incorrectly be interpreted as a spillover.

We therefore consider the FSVAR model consisting of the VAR model (3) in which the errors have the factor structure,

$$
v_{t}=\Gamma f_{t}+\xi_{t}, \text { where } E\left(f_{t} f_{t}^{\prime}\right)=\operatorname{diag}\left(\sigma_{f_{1}}, \ldots, \sigma_{f_{k}}\right) \text { and } E\left(\xi_{t} \xi_{t}^{\prime}\right)=\operatorname{diag}\left(\sigma_{\xi_{1}}, \ldots, \sigma_{\xi_{7}}\right) \text {, }
$$

where $f_{t}$ are the common international factors, $\Gamma$ is the $7 \times k$ matrix of factor loadings, and $\xi_{t}$ are the country-specific, or idiosyncratic, shocks. In (5), common international shocks or factors are identified as those shocks that affect international output contemporaneously.

The FSVAR specification (5) is overidentified, so that empirical evidence can be brought to bear on the number of factors $k$. Tests of the overidentifying restrictions are summarized in Table 5. In both subsamples and in the pooled full sample, the hypothesis of $k=1$ is rejected against the unrestricted alternative (that is, against $\Sigma_{v}$ having full rank) at the $1 \%$ significance level, but the null hypothesis of $k=2$ is not rejected at the $10 \%$ significance level. These results suggest that $k=2$ is appropriate, so we adopt a specification with two common international shocks.

For the decompositions and counterfactual calculations in Sections 6.2 and 6.3, we need to adopt a further normalization to identify separately the factor loadings $\Gamma$ and the variances of the common shocks. The specific normalization we adopt is that the first factor has contemporaneous unit effect on US GDP, that is, $\Gamma_{\mathrm{US}, 1}=1$; and that the second factor has immediate unit effect on France but does not immediately affect the US, so $\Gamma_{\text {France, } 1}=1$ and $\Gamma_{\mathrm{US}, 2}=0$. 


\section{Empirical Results}

This section presents empirical results based on the FSVAR, including an analysis of the sensitivity of the results to some modeling decisions.

\subsection{Changing Importance of Common and Country-Specific Shocks}

The factor structure permits a decomposition of the $h$-step ahead forecast error for GDP growth in a given country into three sources: unforeseen common shocks, unforeseen domestic shocks, and spillover effects of unforeseen domestic shocks to other G7 countries. Because the country shocks and the common shocks are all uncorrelated by assumption, this decomposition in turn permits a threefold decomposition of the variances of the $h$-step ahead forecast error. This approach also can be used to decompose the variance of BP-filtered GDP.

Table 6 summarizes these variance decompositions for GDP growth and for BPfiltered GDP. At the one-quarter horizon, international spillovers account for none of the GDP growth forecast error variance: this is the assumption used to identify the international shock. At longer horizons, spillovers typically account for between 5\% and $15 \%$ of the variance of GDP growth, depending on the country and the subsample. Most of the variance of GDP growth is attributed to the common and idiosyncratic domestic shocks, but the breakdown between these varies considerably across countries. In the first period, the effects of international shocks at the four-quarter horizon are estimated to be the greatest for Canada, France, and Germany, and the least for Italy and Japan. In the second period, almost all the forecast error variance in Japan is attributed to domestic shocks, a result consistent with the declining correlation between GDP in Japan and in other countries in the second period reported in Section 4.

One measure of the degree of exposure of domestic economies to international sources of fluctuations, either common shocks or spillovers, is the share of the forecast error variance attributed to domestic shocks; a small domestic share corresponds to a relatively larger role for international rather than domestic disturbances. By this measure, the international exposure of Canada and Italy has increased substantially and the exposure of Germany and the US has increased moderately, but the effect on Japan of 
international linkages has dropped to less than 5\%. The variance decompositions for BPfiltered GDP yield similar conclusions to the variance decompositions of GDP growth at the 4- and 8-quarter ahead horizon.

Figure 8 presents time-varying estimates of the variance decomposition of BPfiltered GDP, based on rolling estimates FSVAR (as before, using exponential weighting). The units in Figure 8 are those of the variance; the lower line is the contribution to the variance of the international shocks, the middle line is the sum of the contributions of the international shocks and spillovers, and the top line is total variance, so the gap between the top and middle lines is the contribution to the variance of domestic shocks. For Germany, the UK, and the US, the recent decline in the overall volatility tracks a decline in the variance arising from international shocks. For Italy, the large historical decline in the variance is associated with a declining importance of domestic shocks. For Japan, international shocks have become unimportant, and domestic shocks explain nearly all of its volatility in the 1990s and are the source of its recent increase in volatility.

The correlations presented in Section 4 suggest the emergence of a Euro-zone cluster in the second period. This suggests that the second period might have seen the emergence of a "Euro-zone only" factor. The hypothesis that one of the common factors loads only on France, Germany, and Italy provides three testable restrictions on the FSVAR. In the FSVAR estimated over 1960 - 1983, this restriction is rejected at the 5\% significance level $(p=.02)$, but when estimated over $1984-2001$, the restriction is not rejected at the $10 \%$ significance level $(p=.31)$. In other words, the hypothesis of a continental Europe factor can be rejected in the first period but not in the second, giving a quantitative meaning to the apparent emergence of the Euro-zone cluster.

\subsection{Changes in Volatility: Impulse or Propagation?}

In principle, the contribution of international shocks to output volatility could decrease because the variance of the international shocks has decreased, because a shock of a fixed magnitude has less of an effect on the economy, or both. Said differently, the variance of GDP growth in a given country can change because the magnitude of the 
shocks impinging on that economy have changed or because the effects of those shocks have changed.

In this section, we decompose the change in the variance from the first subsample to the second into changes in the magnitudes of the shocks ("impulses") and changes in their effect on the economy ("propagation"). To make this precise, let $V_{p}$ denote the variance of the 4-quarter-ahead forecast errors in a given country in period $p$, where $p=$ 1, 2 corresponds to $1960-1983$ and $1984-2002$. The variance decomposition attributes a portion of $V_{p}$ to each of the nine shocks in the model, so we can write, $V_{p}=V_{p, 1}+\ldots+$ $V_{p, 9}$, where $V_{p, j}$ is the variance in period $p$ attributed to the $j^{\text {th }}$ shock. Thus the change in the variance between the two periods is $V_{2}-V_{1}=\left(V_{2,1}-V_{1,1}\right)+\ldots+\left(V_{2,9}-V_{1,9}\right)$. In identified structural VARs, the variance component $V_{p, j}$ always can be written as $a_{p j} \sigma_{p j}^{2}$, where $a_{p j}$ is a term depending on the squared cumulative impulse response of GDP to shock $j$ in period $p$ and $\sigma_{p j}^{2}$ is the variance of shock $j$ in period $p$. Thus the change in the contribution of the $j^{\text {th }}$ shock can be decomposed exactly as,

$$
V_{2, j}-V_{1, j}=\left(\frac{a_{1 j}+a_{2 j}}{2}\right)\left(\sigma_{2 j}^{2}-\sigma_{1 j}^{2}\right)+\left(\frac{\sigma_{1 j}^{2}+\sigma_{2 j}^{2}}{2}\right)\left(a_{2 j}-a_{1 j}\right) .
$$

That is, the change in the variance can be decomposed into the contribution from the change in the shock variance plus the contribution from the change in the impulse response. The decomposition (6) is additive so these contributions can be aggregated into variance changes arising from the common shocks, spillovers, and own shocks, with each type of shock in turn decomposed into changes in variances arising from changing shock variances and from changing impulse responses; this yields a six-way decomposition of the change in the variance of GDP forecast errors from the first period to the second.

Table 7 presents this six-way decomposition of the change in variances of four quarter-ahead forecast errors in GDP. Evidently, the decline in the variance between the two periods is to a great extent attributed to a decline in the magnitudes of the shocks. Indeed, for Canada, France, the UK, and the US, the decline in the shock variances more than accounts for the drop in the variance of GDP forecast errors, in the sense that 
changes in the propagation mechanism worked to increase rather than decrease the total variance across these two periods. For Germany and Italy, the net contribution of changes in propagation is small, so that most of the variance reductions in Germany and Italy are attributed to changes in the magnitudes of the shocks. The exception here, as we have seen in other aspects of this analysis, is Japan, in which the decline in the variance is largely attributed to changes in the propagation mechanism, not to changes in the size of shocks. Among the different types of shocks, reductions in the size of international shocks played a substantial role in the volatility moderation in all countries but Japan (where the international shock is estimated to have negligible effect). In addition, in all countries a small but nonzero portion of the moderation in all is attributed to smaller foreign idiosyncratic shocks.

One lesson from Table 7 is that there have been important changes in the effect of an international shock of a fixed magnitude on some of these economies. This changing effect is examined further in Figure 9, which presents the impulse response functions for the different countries in the two subsamples with respect to the first common factor (Figure 9a) and the second common factor (Figure 9b). The most noticeable feature is that for many countries, in particular the Canada, France, the UK, and the US, there is a large estimated increase in the magnitude of the effect of the common shocks and in their persistence. Again, Japan is different than the rest of the G7, with the estimated responses to both shocks being nonzero in the first period but nearly zero in the second. ${ }^{5}$

\subsection{Counterfactuals: Second Period Propagation, First Period Shocks}

The foregoing results indicate that much of the moderation is attributable to declines in the variance of the common international shocks. This raises the counterfactual question: what would the volatility and cross-correlations have been in 1984 - 2002, had the G7 economies been confronted with common international shocks as large as they experienced in $1960-1983$ ?

\footnotetext{
${ }^{5}$ The impulse response functions in Figure 9 apply to the normalization of the two common shocks discussed at the end of Section 5. Although different normalizations would yield different impulse response functions, they would be linear combinations of the impulse response functions in Figure 9, and the discussion about persistence in this paragraph would apply to those linear combinations as well.
} 
This counterfactual question can be addressed by suitably combining the impulse responses from the second period FSVAR with the shock variances from the first period FSVAR, then computing the implied moments. The resulting estimated variances are summarized in Table 8. Comparing the first line of each panel (the estimated standard deviations based on second-period impulse response functions and second-period shock variances) with the second line (in which the first-period variance of the common shocks is used) reveals that all countries, except again Japan, would have had considerably greater volatility over the past two decades had the world experienced the first-period shocks. For example, the standard deviation of four-quarter GDP growth in the US would have been approximately 2.9 percentage points, compared with the actual value of 1.6 percentage points; the standard deviation of French four-quarter GDP growth, which in reality was essentially constant over the two periods, would have doubled had the second period experienced international shocks of the same magnitude as the first period.

The cross-country correlations implied by this counterfactual scenario are summarized in Table 9. Not surprisingly, had the common shocks been larger in the second period than they actually were, the cross-country correlations would have been higher, and indeed would have been much higher than they were in the first period. Under the counterfactual scenario the correlations typically increase by between .10 and .20 (Japan again being the exception). According to these estimates, had the common shocks in the second period been as large as they were during the first period, international business cycles would have been more highly synchronized than they actually were, and indeed would have been more highly synchronized than there were in the $1960-1983$ period.

\subsection{An examination of the international shocks}

Because moderation of the international shocks appears to be an important source of the moderation in G7 volatility, it is of interest to see if these international shocks can be linked to observable and interpretable time series.

This section examines several candidates for such observable shocks, taken from Stock and Watson (2002a). The first candidate is US monetary policy shocks; although these are domestic shocks, were they to affect other countries within the quarter that they 
occur, then they would be classified as common international shocks in the FSVAR identification scheme. Many methods have been proposed for identifying monetary policy shocks; here, we adopt Christiano, Eichenbaum and Evan's (1997) identification method. The second candidate series is US productivity shocks, identified using Gali's (1999) method; we treat this as a proxy for world productivity shocks. The third set of shocks are innovations to commodity prices, measured here by an aggregate index of commodity prices, an index for food, an index of industrial materials, and an index of sensitive material prices, all for the U.S. The final set of shocks are oil prices, measured in three ways: the nominal growth rate in oil prices (in the US), and Hamilton's (1996) oil price series, which is the larger of zero and the percentage difference between the current price and the maximum price during the past four quarters. For details of construction of these series, see Stock and Watson (2002a).

Table 10 reports the adjusted $R^{2}$, s from a regression of the common factors onto four quarterly leads and lags of the candidate shock series, separately for each of the two subsamples. In the first period, the first common international shock is correlated with the U.S. monetary policy shock and with the oil price measures, but not with the other shocks. Otherwise, however, the adjusted $R^{2}$ s $\mathrm{s}$ are nearly zero or are negative, indicating that the common international shocks in the FSVAR are in these cases unrelated to these candidate observable shocks. Several of the candidate shocks examined in Table 10 are U.S.-centric and an obvious next step is to examine alternative measures of global shocks.

\subsection{Sensitivity analysis}

This section reports the results of two checks of the foregoing results to changes in the modeling assumptions or in the precise statistics reported.

Trade-weighted VAR lag restrictions. As a check, we considered a further restriction of the VAR in which the coefficients on foreign GDP are proportional to trade shares. Elliott and Fatás (1996) used a similar restriction to identify shocks in a structural VAR, and Norrbin and Schlagenhauf (1996) used it (as we do here) to simplify the lag dynamics. Accordingly, the restricted reduced form VAR is, 


$$
Y_{t}=b(\mathrm{~L}) Y_{t-1}+d(\mathrm{~L}) W Y_{t-1}+v_{t}, \text { where } E v_{t} v_{t}^{\prime}=\Sigma
$$

where $b(\mathrm{~L})$ and $d(\mathrm{~L})$ are $7 \times 1$ vector lag polynomials and $W$ is a fixed weighting matrix, where the diagonal elements of $W$ are zero and the $(i, j)$ element is the share of gross trade (imports plus exports) of trading partner $j$ in all of country $i$ 's trade with $\mathrm{G} 7$ countries. ${ }^{6}$

In the restricted reduced form VAR (7), the number of coefficients per equation equals the number of own lags (the degree of $b(\mathrm{~L}))$ plus the number of lags on tradeweighted foreign GDP (the degree of $d(\mathrm{~L})$ ). AIC and BIC comparisons point to 4 own lags and 1 lag of trade-weighted foreign GDP growth. The FSVAR corresponding to (7) imposes the factor structure (5) on the reduced form errors in (7).

As a gauge of the sensitivity of the results in the previous sections, we recomputed the counterfactual variances and correlations of Tables 8 and 9 for the tradeweighted FSVAR; the results are reported in Tables 11 and 12. Although the numerical values for the estimated changes in variances in Tables 8(a) and 11 differ, the qualitative conclusions are the same. In most countries, the variances of four-quarter GDP growth would have been considerably larger had second-period shocks been as large as firstperiod shocks. The main differences between the standard deviations in Tables 8(a) and 11 is the estimated increase for the UK, which is less using the trade-weighted FSVAR than the base case FSVAR in Table 8(a). The main differences between the implied correlations in Tables 9 and 12 is that the model-based estimates in Table 12(a) (estimates of actuals, not counterfactuals) in some cases differ considerably from the actual sample correlations in Table 4(a): the average absolute difference between the two correlations is .18, almost twice the average of .10 for the $\operatorname{FSVAR}(4,1)$. The tradeweighted model especially fails to capture the correlations involving Canada. In this sense, the trade-weighted FSVAR does not fit the data as well as the FSVAR $(4,1)$. Still, the main conclusion from Table 9 - that international synchronization would have been substantially greater had the common shocks in the second period been as large as they were in the first - also obtains using the trade-weighted FSVAR.

Measuring synchronization by average coherences. The analysis of international synchronization so far has relied on contemporaneous cross-correlations of 
four-quarter GDP growth and of BC-filtered GDP as the measures of comovements, but this can mask lagged associations. An alternative measure of comovements, which is invariant to these lagged effects, is the average coherence at business cycle frequencies. Specifically, let $\omega_{0}$ and $\omega_{1}$ be the lower and upper frequencies that define the business cycle portion of the spectrum, and let $s_{i j}^{(4)}(\omega)$ be the cross-spectrum between the four quarter growth rates in countries $i$ and $j$ as in (4). One measure of the average coherence between four-quarter growth rates in countries $i$ and $j$ at business cycle frequencies is,

$$
R_{i j}^{2}\left(\omega_{0}, \omega_{1}\right)=\frac{\int_{\omega_{0}}^{\omega_{1}}\left\|s_{i j}^{(4)}(\omega)\right\|^{2} d \omega}{\left(\int_{\omega_{0}}^{\omega_{1}}\left\|s_{i i}^{(4)}(\omega)\right\|^{2} d \omega\right)^{1 / 2}\left(\int_{\omega_{0}}^{\omega_{1}}\left\|s_{j j}^{(4)}(\omega)\right\|^{2} d \omega\right)^{1 / 2}} .
$$

This measure reduces to the usual definition of the coherence when it is evaluated at a single frequency rather than over the range $\omega_{0}$ to $\omega_{1}$.

The square root of average coherence $(8), R_{i j}\left(\omega_{0}, \omega_{1}\right)$, was computed for the counterfactual correlations examined in Table 9, and the results are summarized in Table 13 (because the coherence has the interpretation of an $R^{2}$, using the square root of the average coherence makes this measure more directly comparable to the correlations of Table 9). Comparing panel (a) of Tables 9 and 13 shows that the coherences are higher than the correlations of four-quarter growth rate, which is not surprising because the coherences are not sensitive to phase shifts and also focus on business cycle frequencies, whereas the four-quarter growth rates contain some higher frequency noise. The qualitative conclusions from the counterfactual exercise, however, are the same as those drawn from Table 9: under the counterfactual scenario, average business cycle coherences increase, typically by .10 to .15 . In general, findings based on the contemporaneous correlations and the average coherence will be different. As it happens, however, the cross-country lead-lag relations evidently are modest, so these different measures give similar results.

\footnotetext{
${ }^{6}$ Bilateral import and export data are from the IMF's IFS database.
} 


\section{Discussion and Conclusion}

These empirical results suggest four broad conclusions. First, although there has not been a general increase in international synchronization among G7 business cycles, there have been important changes, in particular the emergence of two groups, one consisting of Euro-zone countries and the other of English-speaking countries, within which correlations have increased and across which correlations have decreased. Over this period, cyclical movements in the UK became less correlated with Euro-zone countries and more correlated with North American countries.

Second, common international shocks have been smaller in the 1980s and 1990s than they were in the 1960s and 1970s. According to the FSVAR, this declining volatility of common G7 shocks is the source of much of the observed moderation in individual country business cycles. Moreover, this moderation of common G7 shocks is responsible, in a mechanical sense, for the failure of business cycles to become more synchronous as one might expect given the large increase in trade over this period: had world shocks been as large in the 1980s and 1990s as they were in the 1960s and 1970s, international cyclical correlations would have increased considerably.

Third, the Japanese experience is in many ways exceptional. For the other G7 countries, volatility generally decreased or at least stayed constant in the 1990s, but it increased in the 1990s in Japan. During the 1980s and 1990s, cyclical fluctuations in Japanese GDP became almost detached from the other G7 economies, with domestic shocks explaining almost all of the cyclical movements in Japanese GDP. This finding is consistent with Asian trade being increasingly important for the Japanese economy and with the domestic nature of the economic difficulties Japan experienced in the 1990s.

Fourth, a robust finding is that, however measured, persistence of disturbances both reduced-form innovations and structural shocks - has increased in Canada, France, the UK. In those countries, a shock of a given magnitude would result in more cyclical volatility today than thirty years ago.

This analysis has focused on documenting the changes in the magnitudes of shocks and their effects. An important next step is sorting out the reasons for these changes and their implications for economic policy. 


\section{References}

Ahmed, S., A. Levin and B. Wilson (2001), "Recent U.S. Macroeconomic Stability: Good Luck, Good Policies, or Good Practices?” manuscript, FRB BOG.

Altonji, J. and J. Ham (1990), "Employment Variation in Canada: The Role of External, Regional and Industrial Factors," Journal of Labor Economics, January, SS198236.

Andrews, Donald W.K. (1993), “Tests of Parameter Instability and Structural Change with Unknown Change Point," Econometrica, 61, 821-856.

Artis, M.J., Z.G. Kontolemis, and D.R. Osborn (1997), "Business Cycles for G7 and European Countries,” Journal of Business 70, 249 - 279.

Artis, M.J. and W. Zhang (1997), "International Business Cycles and the ERM: IS there a European Business Cycle," International Journal of Finance and Economics 2, $1-16$.

Artis, M.J. and W. Zhang (1999), "Further Evidence on the International Business Cycle and the ERM: Is there a European Business Cycle?" Oxford Economic Papers $51,120-132$.

Bai, J. (1997), "Estimation of a Change Point in Multiple Regression Models," Review of Economics and Statistics 79, 551-563.

Blanchard, O. and J. Simon (2001), "The Long and Large Decline in U.S. Output Volatility," Brookings Papers on Economic Activity 2001:1, 135 - 164.

Carvalho, V.M. and A.C. Harvey (2002, "Convergence and Cycles in the Euro-Zone," manuscript, University of Cambridge.

Christiano, L., M. Eichenbaum and C. Evans (1997), "Sticky Price and Limited Participation Models of Money: A Comparison," European Economic Review, $41 \mathrm{~m} \mathrm{1201-1249.}$

Clark, T. and K. Shin (2000), “The Sources of Fluctuations Within and Across Countries," in G. Hess and E. van Wincoop (eds.), Intranational Macroeconomics, Cambridge, UK: Cambridge University Press. 
Dalsgaard, T., J. Elmeskov, and C-Y Park (2002), "Ongoing Changes in the Business Cycle - Evidence and Causes," OECD Economics Department Working Paper no. 315.

Del Negro, M. and C. Otrok (2003), "Time-Varying European Business Cycles,” manuscript, University of Virginia.

van Dijk, D., D.R. Osborn, and M. Sensier (2002), "Changes in the Variability of the Business Cycle in the G7 Countries," manuscript, Erasmus University Rotterdam

Doyle, B. and J. Faust (2002a), "An Investigation of Co-movements among the Growth Rates of the G-7 Countries," Federal Reserve Bulletin, October 2002, 427 - 437.

Doyle, B. and J. Faust (2002b), "Breaks in the Variability and Co-Movement of G-7 Economic Growth," manuscript, Federal Reserve Board.

Elliott, G. and A. Fatás (1996), "International Business Cycles and the Dynamics of the Current Account," European Economic Review 40, 361 - 387.

Forni, M., M. Hallin, M. Lippi, and L. Reichlin (2000), "The Generalized Dynamic Factor Model: Identification and Estimation," The Review of Economics and Statistics 82, 540-552.

Fritsche, U. and V. Kouzine (2003), "Declining Output Volatility and Monetary Policy in Germany," manuscript, German Institute for Economic Research (DIW Berlin).

Gali, J. (1999), “Technology, Employment and the Business Cycle: Do Technology Shocks Explain Aggregate Productivity," American Economic Review, 89, 249271.

Hamilton, J.D. (1996), "This is What Happened to the Oil Price-Macroeconomy Relationship," Journal of Monetary Economics 38, no. 2: 215-20.

Heathcoate, J. and F. Perri (2002), "Financial Globalization and Real Regionalization," NBER Working Paper 9292.

Helbling, T. and T. Bayoumi (2003), “Are They All in the Same Boat? The 2000-2001 Growth Slowdown and the G-\& Business Cycle Linkages," manuscript, International Monetary Fund.

Helg, R., P. Manasse, T. Monacelli, and R. Roveli (1995), "How Much (A)symmetry in Europe? Evidence from Industrial Sectors," European Economic Review 39, 1017 $-1041$. 
Kim, C.-J. and C.R. Nelson (1999), "Has the U.S. Economy Become More Stable? A Bayesian Approach Based on a Markov-Switching Model of the Business Cycle," The Review of Economics and Statistics 81, 608 - 616.

Kose, M.A., C. Otrok, and C.H. Whiteman (2001), "International Business Cycles: World, Region, and Country-Specific Factors," forthcoming, American Economic Review.

Kose, M.A., E.S. Prasad, and M.E. Terrones (2003), "How Does Globalization Affect the Synchronization of Business Cycles?,” IZA Discussion Paper no. 702.

Luginbuhl, R. and S.J. Koopman (2003), "Convergence in European GDP Series: A Multivariate Common Converging Trend-Cycle Decomposition," Tinbergen Institute Discussion Paper 2003-031/4.

McConnell, M.M and G. Perez-Quiros, (2000), "Output Fluctuations in the United States: What has Changed Since the Early 1980's," American Economic Review, Vol. 90, No. 5, 1464-1476.

Mills, T.C. and P. Wang (2000), "Searching for the Sources of Stabilisation in Output Gorwth Rates: Evidence from the G-7 Economies," manuscript.

Monfort, A., J.P. Renne, R. Rüffer, and G. Vitale (2002), "Is Economic Activity in the G7 Synchronized? Common Shocks vs. Spillover Effects," manuscript.

Norrbin, S.C. and D.E. Schlagenhauf (1996), "The Role of International Factors in the Business Cycle: A Multi-Country Study," Journal of International Economics 40, $84-104$.

Prasad, E.S. and R.L. Lumsdaine (2003), "Identifying the Common Component of International Economic Fluctuations: A New Approach,” Economic Journal 113, $101-127$.

Simon, J. (2001), "The Decline in Australian Output Volatility,” manuscript, Reserve Bank of Australia

Stock, J.H. and M.W. Watson (1998), “Asymptotically Median Unbiased Estimation of Coefficient Variance in a Time Varying Parameter Model," Journal of the American Statistical Association 93, 349-358.

Stock, J.H. and M.W. Watson (2002a), "Has the Business Cycle Changed and Why?" forthcoming, NBER Macroeconomics Annual 2002. 
Stock, J.H. and M.W. Watson (2002b), "Forecasting Using Principal Components from a Large Number of Predictors," Journal of the American Statistical Association 97, $1167-1179$. 


\section{Table A.1 Sources for GDP Data}

Real GDP series were used for each of the G7 countries for the sample period 1960:1-2002:4. A consistent series over the entire sample period did not exist for Canada, France and Italy, and in these cases two series were spliced. The table below gives the data sources and sample periods for each data series used. Abbreviations used the source column are (DS) DataStream, (DRI) Data Resources and (E) for an internal OECD series from Dalsgaard, Elmeskov, and Park (2002). ${ }^{7}$

\begin{tabular}{|l|l|l|l|}
\hline Country & Series Name & Source & Sample period \\
\hline Canada & cnona017g & OECD (DS) & $1960: 11960: 4$ \\
& cngdp...d & STATISTICS CANADA (DS) & $1961: 12002: 4$ \\
\hline France & frona017g & OECD (DS) & $1960: 11977: 4$ \\
& frgdp...d & I.N.S.E.E. (DS) & $1978: 12002: 4$ \\
\hline Germany & bdgdp,.,d & DEUTSCHE BUNDESBANK (DS) & $1960: 12002: 4$ \\
\hline Italy & & OECD (E) & $1960: 11969: 4$ \\
& itgdp...d & ISTITUTO NAZIONALE DI STATISTICA (DS) & $1970: 12002: 4$ \\
\hline Japan & jpona017g & OECD (DS) & $1960: 12002: 4$ \\
\hline UK & ukgdp...d & OFFICE FOR NATIONAL STATISTICS (DS) & $1960: 12002: 4$ \\
\hline US & gdpq & Dept. of Commerce (DRI) & $1960: 12002: 4$ \\
\hline
\end{tabular}

Table 1. Mean and Standard Deviations of 4-quarter GDP growth in the G7 by decade

\begin{tabular}{|l|c|l|l|l|l|l|l|l|}
\hline & \multicolumn{9}{|l|}{ Mean growth rate } & \multicolumn{3}{l|}{$\begin{array}{l}\text { Standard deviation of } \\
\text { 4-quarter growth }\end{array}$} \\
& \multicolumn{9}{|l|}{-quarle } \\
\hline & $60-69$ & $70-79$ & $80-89$ & $90-02$ & $60-69$ & $70-79$ & $80-89$ & $90-02$ \\
\hline Canada & 3.11 & 2.54 & 1.71 & 1.52 & 1.83 & 1.82 & 2.67 & 2.24 \\
\hline France & 4.07 & 2.97 & 1.78 & 1.33 & 1.24 & 1.66 & 1.27 & 1.43 \\
\hline Germany & 3.83 & 2.59 & 1.57 & 1.31 & 2.56 & 2.13 & 1.67 & 1.53 \\
\hline Italy & 4.55 & 3.61 & 2.17 & 1.32 & 2.34 & 3.14 & 1.33 & 1.30 \\
\hline Japan & 8.65 & 3.55 & 3.21 & 1.21 & 2.19 & 3.16 & 1.57 & 2.08 \\
\hline UK & 2.35 & 2.20 & 2.12 & 1.84 & 1.84 & 2.48 & 2.51 & 1.60 \\
\hline US & 2.95 & 2.20 & 2.00 & 1.62 & 2.09 & 2.74 & 2.66 & 1.47 \\
\hline
\end{tabular}

Notes: The columns labeled "Mean growth rate" show the sample mean of $400 \times \ln \left(G D P_{t}\right.$ $\left./ G D P_{t-1}\right)$. The "Standard deviation" columns show the standard deviation of $100 \times\left(G D P_{t} / G D P_{t-4}\right)$.

${ }^{7}$ We thank Brain Doyle and Jon Faust for advice and for supplying us with the Dalsgaard, Elmeskov, and Park (2002) data. 


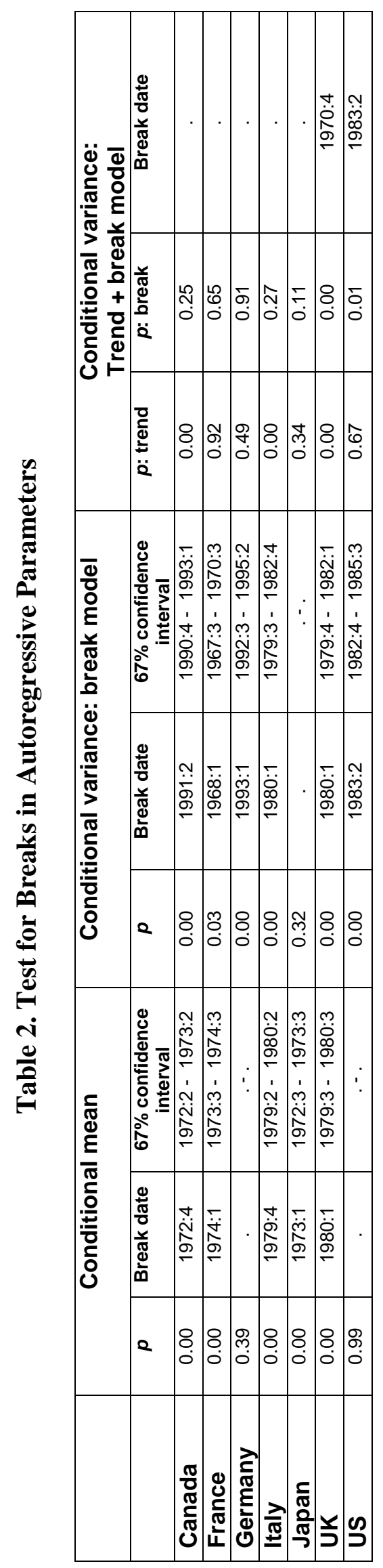


Table 3. Autoregressive Parameters for GDP growth rates:

Sums of AR coefficients and standard error of the regression

$$
\Delta y_{t}=\alpha(\mathrm{L}) \Delta y_{t-1}+\varepsilon_{t}
$$

\begin{tabular}{|l|c|c|c|c|}
\hline & \multicolumn{2}{|c|}{$\hat{\alpha}(1)$} & \multicolumn{2}{c|}{$\hat{\sigma}_{\varepsilon}$} \\
\hline & $\mathbf{1 9 6 0 - 1 9 8 3}$ & $\mathbf{1 9 8 4 - 2 0 0 2}$ & $\mathbf{1 9 6 0 - 1 9 8 3}$ & $\mathbf{1 9 8 4 - \mathbf { 2 0 0 2 }}$ \\
\hline Canada & 0.00 & 0.56 & 3.82 & 2.27 \\
\hline France & -0.36 & 0.43 & 2.95 & 1.79 \\
\hline Germany & 0.04 & -0.18 & 5.42 & 3.39 \\
\hline Italy & 0.02 & 0.13 & 4.03 & 2.16 \\
\hline JP & 0.38 & 0.09 & 4.08 & 3.79 \\
\hline UK & 0.03 & 0.65 & 4.81 & 1.84 \\
\hline US & 0.30 & 0.47 & 3.98 & 1.96 \\
\hline
\end{tabular}

Notes: Estimates are computed using detrended GDP growth. 
Table 4. Cross-country GDP growth correlations

(a) Four-quarter growth rates, simple correlation coefficients

\begin{tabular}{|c|c|c|c|c|c|c|c|}
\hline & Canada & France & Germany & Italy & Japan & UK & US \\
\hline & \multicolumn{7}{|c|}{$1960-1983$} \\
\hline Canada & 1.00 & & & & & & \\
\hline France & 0.31 & 1.00 & & & & & \\
\hline Germany & 0.50 & 0.56 & 1.00 & & & & \\
\hline Italy & 0.30 & 0.59 & 0.35 & 1.00 & & & \\
\hline Japan & 0.20 & 0.40 & 0.46 & 0.28 & 1.00 & & \\
\hline UK & 0.26 & 0.54 & 0.53 & 0.13 & 0.48 & 1.00 & \\
\hline \multirow[t]{2}{*}{ US } & 0.77 & 0.39 & 0.52 & 0.21 & 0.32 & 0.46 & 1.00 \\
\hline & \multicolumn{7}{|c|}{$1984-2002$} \\
\hline Canada & 1.00 & & & & & & \\
\hline France & 0.33 & 1.00 & & & & & \\
\hline Germany & 0.12 & 0.59 & 1.00 & & & & \\
\hline Italy & 0.38 & 0.77 & 0.59 & 1.00 & & & \\
\hline Japan & -0.05 & 0.28 & 0.38 & 0.34 & 1.00 & & \\
\hline UK & 0.72 & 0.33 & 0.11 & 0.47 & 0.09 & 1.00 & \\
\hline US & 0.80 & 0.26 & 0.22 & 0.29 & 0.02 & 0.58 & 1.00 \\
\hline
\end{tabular}

(b) Four-quarter growth rates, implied by reduced form VAR $(4,1)$

\begin{tabular}{|c|c|c|c|c|c|c|c|}
\hline & Canada & France & Germany & Italy & Japan & UK & US \\
\hline & \multicolumn{7}{|c|}{$1960-1983$} \\
\hline Canada & 1.00 & & & & & & \\
\hline France & 0.31 & 1.00 & & & & & \\
\hline Germany & 0.57 & 0.56 & 1.00 & & & & \\
\hline Italy & 0.35 & 0.52 & 0.33 & 1.00 & & & \\
\hline Japan & 0.33 & 0.29 & 0.39 & 0.22 & 1.00 & & \\
\hline UK & 0.31 & 0.52 & 0.50 & 0.12 & 0.44 & 1.00 & \\
\hline \multirow[t]{2}{*}{ US } & 0.72 & 0.38 & 0.53 & 0.20 & 0.33 & 0.42 & 1.00 \\
\hline & \multicolumn{7}{|c|}{$1984-2002$} \\
\hline Canada & 1.00 & & & & & & \\
\hline France & 0.56 & 1.00 & & & & & \\
\hline Germany & 0.09 & 0.54 & 1.00 & & & & \\
\hline Italy & 0.45 & 0.79 & 0.49 & 1.00 & & & \\
\hline Japan & -0.02 & 0.15 & 0.33 & 0.13 & 1.00 & & \\
\hline UK & 0.70 & 0.58 & 0.18 & 0.56 & 0.03 & 1.00 & \\
\hline US & 0.81 & 0.64 & 0.24 & 0.42 & 0.04 & 0.68 & 1.00 \\
\hline
\end{tabular}


Table 4, continued

(c) BP-filtered GDP, implied by reduced form $\operatorname{VAR}(4,1)$

\begin{tabular}{|c|c|c|c|c|c|c|c|}
\hline & Canada & France & Germany & Italy & Japan & UK & US \\
\hline & \multicolumn{7}{|c|}{$1960-1983$} \\
\hline Canada & 1.00 & & & & & & \\
\hline France & 0.36 & 1.00 & & & & & \\
\hline Germany & 0.62 & 0.60 & 1.00 & & & & \\
\hline Italy & 0.39 & 0.56 & 0.37 & 1.00 & & & \\
\hline Japan & 0.35 & 0.31 & 0.41 & 0.24 & 1.00 & & \\
\hline UK & 0.34 & 0.56 & 0.55 & 0.15 & 0.47 & 1.00 & \\
\hline \multirow[t]{2}{*}{ US } & 0.76 & 0.44 & 0.59 & 0.23 & 0.34 & 0.46 & 1.00 \\
\hline & \multicolumn{7}{|c|}{$1984-2002$} \\
\hline Canada & 1.00 & & & & & & \\
\hline France & 0.50 & 1.00 & & & & & \\
\hline Germany & 0.08 & 0.59 & 1.00 & & & & \\
\hline Italy & 0.42 & 0.79 & 0.53 & 1.00 & & & \\
\hline Japan & -0.03 & 0.20 & 0.42 & 0.18 & 1.00 & & \\
\hline UK & 0.68 & 0.51 & 0.15 & 0.54 & 0.04 & 1.00 & \\
\hline US & 0.79 & 0.59 & 0.23 & 0.37 & 0.07 & 0.64 & 1.00 \\
\hline
\end{tabular}

Notes: The correlations implied by the reduced form $\operatorname{VAR}(4,1)$ were computed from the VAR coefficients and variance matrix estimated over the two subsamples. The correlations for BP-filtered GDP were computed for the ideal BP filter.

Table 5. Tests of $\boldsymbol{k}$-factor Model versus Unrestricted Error Covariance Matrix

\begin{tabular}{|c|c|c|c|c|c|c|c|}
\hline Number of & d.f. & \multicolumn{2}{|c|}{$1960-2002$} & \multicolumn{2}{c|}{$1960-1983$} & \multicolumn{2}{|c|}{$1964-2002$} \\
\cline { 2 - 8 } Factors $(k)$ & $\begin{array}{c}\text { LR } \\
\text { Statistic }\end{array}$ & $p$-value & $\begin{array}{c}\text { LR } \\
\text { Statistic }\end{array}$ & $p$-value & $\begin{array}{c}\text { LR } \\
\text { Statistic }\end{array}$ & $p$-value \\
\hline & & & & & & & \\
\hline 1 & 14 & 47.32 & 0.00 & 33.36 & 0.00 & 39.29 & 0.00 \\
\hline 2 & 8 & 12.78 & 0.12 & 13.05 & 0.11 & 12.68 & 0.12 \\
\hline 3 & 3 & 2.25 & 0.52 & 2.69 & 0.45 & 1.59 & 0.66 \\
\hline
\end{tabular}

Notes: Entries are the likelihood ratio test statistic and its $p$-value testing the null hypothesis that the $\operatorname{VAR}(4,1)$ error covariance matrix has a $k$-factor structure, against the unrestricted alternative. The degrees of freedom of the test are given in the second column. 
Table 6. Variance Decompositions: Common Shocks, Spillovers, and Own-Country Shocks

(a) Forecast Error Variance Decompositions for GDP Growth

\begin{tabular}{|c|c|c|c|c|c|c|c|c|c|}
\hline & & \multicolumn{4}{|c|}{$1960-1983$} & \multicolumn{4}{|c|}{$1984-2002$} \\
\hline & horizon & $\begin{array}{l}\text { standard } \\
\text { deviation }\end{array}$ & Factor & Spillover & Own & $\begin{array}{l}\text { standard } \\
\text { deviation }\end{array}$ & Factor & Spillover & Own \\
\hline Canada & 1 & 3.37 & 0.36 & 0.00 & 0.64 & 2.04 & 0.97 & 0.00 & 0.03 \\
\hline & 2 & 2.70 & 0.45 & 0.09 & 0.46 & 1.77 & 0.92 & 0.05 & 0.03 \\
\hline & 4 & 2.01 & 0.50 & 0.16 & 0.34 & 1.71 & 0.89 & 0.09 & 0.02 \\
\hline & 8 & 1.43 & 0.52 & 0.17 & 0.31 & 1.59 & 0.83 & 0.15 & 0.02 \\
\hline France & 1 & 2.66 & 0.97 & 0.00 & 0.03 & 1.62 & 0.96 & 0.00 & 0.04 \\
\hline & 2 & 1.90 & 0.87 & 0.11 & 0.02 & 1.23 & 0.93 & 0.04 & 0.03 \\
\hline & 4 & 1.29 & 0.82 & 0.16 & 0.02 & 1.11 & 0.91 & 0.06 & 0.03 \\
\hline & 8 & 0.87 & 0.81 & 0.18 & 0.01 & 1.06 & 0.88 & 0.10 & 0.02 \\
\hline Germany & 1 & 4.81 & 0.24 & 0.00 & 0.76 & 3.12 & 0.26 & 0.00 & 0.74 \\
\hline & 2 & 3.35 & 0.33 & 0.10 & 0.57 & 2.02 & 0.31 & 0.06 & 0.63 \\
\hline & 4 & 2.32 & 0.38 & 0.15 & 0.47 & 1.26 & 0.34 & 0.07 & 0.59 \\
\hline & 8 & 1.73 & 0.41 & 0.16 & 0.43 & 0.90 & 0.39 & 0.08 & 0.53 \\
\hline Italy & 1 & 3.86 & 0.10 & 0.00 & 0.90 & 1.96 & 0.33 & 0.00 & 0.67 \\
\hline & 2 & 3.11 & 0.10 & 0.02 & 0.88 & 1.40 & 0.41 & 0.05 & 0.54 \\
\hline & 4 & 2.42 & 0.12 & 0.04 & 0.84 & 1.09 & 0.45 & 0.08 & 0.47 \\
\hline & 8 & 1.59 & 0.15 & 0.06 & 0.80 & 0.88 & 0.51 & 0.12 & 0.37 \\
\hline Japan & 1 & 3.96 & 0.17 & 0.00 & 0.83 & 3.62 & 0.01 & 0.00 & 0.99 \\
\hline & 2 & 3.01 & 0.19 & 0.02 & 0.79 & 2.52 & 0.00 & 0.03 & 0.97 \\
\hline & 4 & 2.49 & 0.20 & 0.02 & 0.78 & 1.84 & 0.00 & 0.03 & 0.97 \\
\hline & 8 & 1.98 & 0.20 & 0.03 & 0.77 & 1.37 & 0.01 & 0.04 & 0.95 \\
\hline U.K. & 1 & 4.66 & 0.24 & 0.00 & 0.76 & 1.69 & 0.03 & 0.00 & 0.97 \\
\hline & 2 & 3.22 & 0.23 & 0.03 & 0.74 & 1.56 & 0.10 & 0.00 & 0.90 \\
\hline & 4 & 2.35 & 0.24 & 0.03 & 0.72 & 1.31 & 0.20 & 0.02 & 0.78 \\
\hline & 8 & 1.71 & 0.25 & 0.04 & 0.71 & 1.22 & 0.29 & 0.03 & 0.68 \\
\hline U.S. & 1 & 3.95 & 0.27 & 0.00 & 0.73 & 1.74 & 0.22 & 0.00 & 0.78 \\
\hline & 2 & 3.23 & 0.31 & 0.01 & 0.68 & 1.41 & 0.29 & 0.05 & 0.66 \\
\hline & 4 & 2.55 & 0.33 & 0.02 & 0.65 & 1.29 & 0.38 & 0.12 & 0.50 \\
\hline & 8 & 1.84 & 0.35 & 0.02 & 0.63 & 1.20 & 0.47 & 0.17 & 0.36 \\
\hline
\end{tabular}


Table 6, continued

(b) BP-filtered GDP

\begin{tabular}{|l|c|c|c|c|c|c|c|c|}
\hline & \multicolumn{9}{|c|}{$1960-1983$} & \multicolumn{3}{c|}{$1984-2002$} \\
\hline & $\begin{array}{l}\text { standard } \\
\text { deviation }\end{array}$ & Factor & Spillover & Own & $\begin{array}{c}\text { standard } \\
\text { deviation }\end{array}$ & Factor & Spillover & Own \\
\hline Canada & 1.19 & 0.50 & 0.20 & 0.30 & 1.16 & 0.80 & 0.18 & 0.02 \\
\hline France & 0.74 & 0.77 & 0.21 & 0.01 & 0.76 & 0.85 & 0.14 & 0.02 \\
\hline Germany & 1.34 & 0.41 & 0.19 & 0.41 & 0.72 & 0.39 & 0.10 & 0.51 \\
\hline Italy & 1.46 & 0.14 & 0.06 & 0.81 & 0.67 & 0.49 & 0.13 & 0.38 \\
\hline Japan & 1.49 & 0.20 & 0.03 & 0.77 & 1.07 & 0.02 & 0.05 & 0.93 \\
\hline U.K. & 1.33 & 0.25 & 0.05 & 0.71 & 0.86 & 0.33 & 0.05 & 0.62 \\
\hline U.S. & 1.51 & 0.34 & 0.03 & 0.63 & 0.87 & 0.44 & 0.20 & 0.37 \\
\hline
\end{tabular}

Notes: Standard deviations are in percent per year (growth rates) or percentages (BPfiltered). Remaining entries are the fraction of the variance associated with the common factors, with cross-country spillovers, or with the country's own idiosyncratic shocks. Panel (a) presents forecast error variance decompositions at various horizons; panel (b) decomposes the total variance of BP-filtered GDP.

Table 7. Decomposition of changes in the variance of 4-quarter-ahead forecast errors into changing impulses and changing propagation.

\begin{tabular}{|l|c|c|c|c|c|c|c|c|c|c|c|}
\hline & \multicolumn{4}{|c|}{ Variances } & \multicolumn{3}{c|}{$\begin{array}{c}\text { Contribution of change in } \\
\text { shock variance }\end{array}$} & \multicolumn{3}{c|}{$\begin{array}{c}\text { Contribution of change in } \\
\text { impulse response function }\end{array}$} \\
\hline & $\begin{array}{l}1960- \\
1983\end{array}$ & $\begin{array}{l}1984- \\
2002\end{array}$ & change & int'l & $\begin{array}{c}\text { spill- } \\
\text { over }\end{array}$ & own & total & int'l & $\begin{array}{c}\text { spill- } \\
\text { over }\end{array}$ & own & total \\
\hline Canada & 4.06 & 2.93 & -1.13 & -7.45 & -0.71 & -2.40 & -10.56 & 8.03 & 0.31 & 1.09 & 9.43 \\
\hline France & 1.66 & 1.22 & -0.44 & -2.31 & -0.32 & -0.02 & -2.65 & 2.06 & 0.12 & 0.03 & 2.21 \\
\hline Germany & 5.39 & 1.59 & -3.80 & -1.47 & -0.43 & -1.41 & -3.31 & -0.03 & -0.27 & -0.18 & -0.49 \\
\hline Italy & 5.86 & 1.19 & -4.67 & -1.14 & -0.32 & -3.18 & -4.64 & 0.95 & 0.20 & -1.18 & -0.03 \\
\hline Japan & 6.18 & 3.39 & -2.79 & -0.53 & -0.24 & -0.01 & -0.78 & -0.67 & 0.20 & -1.54 & -2.01 \\
\hline U.K. & 5.52 & 1.73 & -3.80 & -1.45 & -0.23 & -5.03 & -6.72 & 0.45 & 0.08 & 2.39 & 2.92 \\
\hline U.S. & 6.51 & 1.66 & -4.84 & -2.56 & -0.54 & -3.26 & -6.36 & 1.03 & 0.62 & -0.13 & 1.52 \\
\hline
\end{tabular}

Notes: The first three columns give the variance of BP-filtered GDP in the first and second subsample, estimated using the FSVAR, and their difference. The remaining columns decompose this difference into changes in the impulse response functions and changes in the variances of the shocks themselves. The sum of the "international," "spillover," and "own" columns equals the "total" column, and the sum of the two "total" columns equals the "change" column. 
Table 8. Counterfactual Volatility Measures during 1984 - 2002 using Common and Country Shock Variances from 1960 - 1983

(a) Standard Deviations of 4-quarter GDP growth

\begin{tabular}{|c|c|c|c|c|c|c|c|c|}
\hline \multicolumn{2}{|c|}{$\begin{array}{l}\text { Period for shock } \\
\text { variances }\end{array}$} & \multicolumn{7}{|c|}{ Standard deviation of 4-quarter GDP growth } \\
\hline $\begin{array}{l}\text { Common } \\
\text { shocks }\end{array}$ & $\begin{array}{l}\text { Country } \\
\text { shocks }\end{array}$ & Canada & France & Germany & Italy & Japan & UK & US \\
\hline $84-02$ & $84-02$ & 2.06 & 1.43 & 1.34 & 1.21 & 1.87 & 1.59 & 1.60 \\
\hline $60-83$ & $84-02$ & 4.63 & 2.94 & 1.94 & 2.04 & 1.96 & 2.61 & 2.92 \\
\hline $60-83$ & $60-83$ & 5.33 & 3.25 & 2.37 & 2.78 & 2.16 & 3.95 & 3.84 \\
\hline
\end{tabular}

(b) Standard Deviations of BP-filtered GDP

\begin{tabular}{|c|c|c|c|c|c|c|c|c|}
\hline $\begin{array}{c}\text { Period for shock } \\
\text { variances }\end{array}$ & \multicolumn{7}{c|}{ Standard deviation of BP-filtered GDP } \\
\hline $\begin{array}{c}\text { Common } \\
\text { shocks }\end{array}$ & $\begin{array}{c}\text { Country } \\
\text { shocks }\end{array}$ & Canada & France & Germany & Italy & Japan & UK & US \\
\hline $84-02$ & $84-02$ & 1.16 & 0.76 & 0.72 & 0.67 & 1.07 & 0.86 & 0.87 \\
\hline $60-83$ & $84-02$ & 2.62 & 1.55 & 1.04 & 1.12 & 1.12 & 1.43 & 1.56 \\
\hline $60-83$ & $60-83$ & 3.01 & 1.70 & 1.27 & 1.52 & 1.22 & 2.16 & 2.08 \\
\hline
\end{tabular}

Notes: Entries in panel (a) are the standard deviations of four-quarter GDP growth based on the FSVAR impulse response functions estimated using data from 1984 - 2002, using the shock variances estimated over the sample indicated in the first two columns. The first row is the model-based estimate of the actual standard deviation during 1984 - 2002; the remaining rows are counterfactuals. The entries in panel (b) are analogous to those in panel (a) but pertain to BP-filtered GDP. 
Table 9. Counterfactual Correlations Between Four-quarter Growth Rates during 1984 - 2002 using Common Shock Variances from 1960 - 1983

(a) FSVAR estimates of actual 1984 - 2002 correlations

\begin{tabular}{|l|c|c|c|c|c|c|c|}
\hline & Canada & France & Germany & Italy & Japan & UK & US \\
\hline Canada & 1.00 &. &. &. &. &. &. \\
\hline France & 0.57 & 1.00 &. &. &. &. &. \\
\hline Germany & 0.10 & 0.55 & 1.00 &. &. &. &. \\
\hline Italy & 0.48 & 0.80 & 0.48 & 1.00 &. &. &. \\
\hline Japan & 0.01 & 0.16 & 0.27 & 0.15 & 1.00 &. &. \\
\hline UK & 0.70 & 0.58 & 0.19 & 0.56 & 0.05 & 1.00 &. \\
\hline US & 0.81 & 0.66 & 0.23 & 0.53 & 0.13 & 0.70 & 1.00 \\
\hline
\end{tabular}

(b) FSVAR estimates of 1984 - 2002 correlations using common shock variances from 1960 - 1983

\begin{tabular}{|l|c|c|c|c|c|c|c|}
\hline & Canada & France & Germany & Italy & Japan & UK & US \\
\hline Canada & 1.00 &. &. &. &. &. &. \\
\hline France & 0.70 & 1.00 &. &. &. &. &. \\
\hline Germany & 0.25 & 0.71 & 1.00 &. &. &. &. \\
\hline Italy & 0.67 & 0.92 & 0.69 & 1.00 &. &. &. \\
\hline Japan & 0.12 & 0.23 & 0.31 & 0.23 & 1.00 &. &. \\
\hline UK & 0.84 & 0.76 & 0.43 & 0.75 & 0.21 & 1.00 &. \\
\hline US & 0.90 & 0.82 & 0.43 & 0.76 & 0.23 & 0.88 & 1.00 \\
\hline
\end{tabular}

Notes: Entries in panel (a) are the correlations among four-quarter GDP growth based on the FSVAR estimated using data from 1984 - 2002. Entries in panel (b) are based on the 1984 - 2002 FSVAR, except calculated using the common shock variances from the 1960 - 1983 FSVAR. 


\section{Table 10. $\bar{R}^{2}$ from Regressions of International Factors onto Various Candidate Shocks}

(a) Factor \#1

\begin{tabular}{|l|c|c|c|}
\hline & $\mathbf{1 9 6 0 - 2 0 0 1}$ & $\mathbf{1 9 6 0 - 1 9 8 3}$ & $\mathbf{1 9 8 4 - 2 0 0 1}$ \\
\hline US Money (CEE) & .094 & .099 & .011 \\
\hline US Productivity (Gali) & .035 & .006 & .046 \\
\hline Com Price: All & .044 & .064 & -.037 \\
\hline Com Price: Food & -.023 & .003 & -.087 \\
\hline Ind. mat's prices & .085 & .105 & .007 \\
\hline Sens. mat's prices & .107 & .128 & -.016 \\
\hline oil price (nominal) & -.028 & .130 & -.070 \\
\hline oil price (Hamilton) & .029 & .115 & -.071 \\
\hline
\end{tabular}

(b) Factor \#2

\begin{tabular}{|l|c|c|c|}
\hline & $\mathbf{1 9 6 0 - 2 0 0 1}$ & $\mathbf{1 9 6 0 - 1 9 8 3}$ & $\mathbf{1 9 8 4 - 2 0 0 1}$ \\
\hline US Money (CEE) & -.004 & -.074 & .013 \\
\hline US Productivity (Gali) & .024 & -.045 & .040 \\
\hline Com Price: All & -.028 & -.088 & -.003 \\
\hline Com Price: Food & -.005 & -.054 & -.056 \\
\hline Ind. mat's prices & -.034 & -.044 & .028 \\
\hline Sens. mat's prices & -.030 & -.048 & .041 \\
\hline oil price (nominal) & -.044 & -.040 & -.035 \\
\hline oil price (Hamilton) & -.006 & -.021 & .001 \\
\hline
\end{tabular}

Notes: Entries are $\bar{R}^{2}$ 's from a regression of common factor \#1 (panel (a)) or \#2 (panel (b)) onto four leads and lags of the series listed in the first column. These series are described in the text. 
Table 11. Counterfactual Standard Deviation of 4-quarter GDP Growth Based on Trade-Weighted FSVAR

\begin{tabular}{|c|c|c|c|c|c|c|c|c|}
\hline \multicolumn{7}{|c|}{$\begin{array}{c}\text { Period for shock } \\
\text { variances }\end{array}$} & \multicolumn{7}{|c|}{ Standard deviation of 4-quarter GDP growth } \\
\hline $\begin{array}{c}\text { Common } \\
\text { shocks }\end{array}$ & $\begin{array}{c}\text { Country } \\
\text { shocks }\end{array}$ & Canada & France & Germany & Italy & Japan & UK & US \\
\hline $84-02$ & $84-02$ & 1.88 & 1.20 & 1.36 & 1.10 & 1.93 & 1.49 & 1.43 \\
\hline $60-83$ & $84-02$ & 3.51 & 2.17 & 1.81 & 1.59 & 2.01 & 1.65 & 2.07 \\
\hline $60-83$ & $60-83$ & 4.15 & 2.20 & 2.26 & 2.25 & 2.16 & 3.39 & 2.89 \\
\hline
\end{tabular}

Notes: Entries are computed in the same way as in panel (a) of Table 8, except they are based on the FSVAR (7) with trade-weight lag restrictions.

Table 12. Sensitivity Check: Counterfactual Correlations of 4-quarter GDP Growth Based on Trade-Weighted FSVAR

(a) Trade-weighted FSVAR estimates of actual 1984 - 2002 correlations

\begin{tabular}{|l|c|c|c|c|c|c|c|}
\hline & Canada & France & Germany & Italy & Japan & UK & US \\
\hline Canada & 1.00 &. &. &. &. &. &. \\
\hline France & 0.22 & 1.00 &. &. &. &. &. \\
\hline Germany & -0.09 & 0.52 & 1.00 &. &. &. &. \\
\hline Italy & 0.15 & 0.68 & 0.43 & 1.00 &. &. &. \\
\hline Japan & 0.20 & 0.11 & 0.10 & 0.08 & 1.00 &. &. \\
\hline UK & 0.15 & 0.35 & 0.20 & 0.24 & 0.07 & 1.00 &. \\
\hline US & 0.75 & 0.34 & 0.09 & 0.24 & 0.30 & 0.17 & 1.00 \\
\hline
\end{tabular}

(b) Trade-weighted FSVAR estimates of $1984-2002$ correlations using common shock variances from 1960 - 1983

\begin{tabular}{|l|c|c|c|c|c|c|c|}
\hline & Canada & France & Germany & Italy & Japan & UK & US \\
\hline Canada & 1.00 &. &. &. &. &. &. \\
\hline France & 0.28 & 1.00 &. &. &. &. &. \\
\hline Germany & -0.14 & 0.64 & 1.00 &. &. &. &. \\
\hline Italy & 0.22 & 0.84 & 0.61 & 1.00 &. &. &. \\
\hline Japan & 0.24 & 0.16 & 0.13 & 0.12 & 1.00 &. &. \\
\hline UK & 0.26 & 0.52 & 0.32 & 0.43 & 0.14 & 1.00 &. \\
\hline US & 0.87 & 0.44 & 0.07 & 0.38 & 0.33 & 0.33 & 1.00 \\
\hline
\end{tabular}

Notes: Entries are computed in the same way as in Table 9, except they are based on the FSVAR (7) with trade-weight lag restrictions. 
Table 13. Sensitivity Check: Counterfactual Coherences Between Four-quarter Growth Rates during 1984 - 2002 using Common Shock Variances from 1960 - 1983

(a) FSVAR estimated actuals for $1984-2002$

\begin{tabular}{|l|c|c|c|c|c|c|c|}
\hline & Canada & France & Germany & Italy & Japan & UK & US \\
\hline Canada & 1.00 &. &. &. &. &. &. \\
\hline France & 0.73 & 1.00 &. &. &. &. &. \\
\hline Germany & 0.32 & 0.61 & 1.00 &. &. &. &. \\
\hline Italy & 0.64 & 0.88 & 0.58 & 1.00 &. &. &. \\
\hline Japan & 0.20 & 0.18 & 0.34 & 0.21 & 1.00 &. &. \\
\hline UK & 0.82 & 0.71 & 0.33 & 0.68 & 0.19 & 1.00 &. \\
\hline US & 0.88 & 0.77 & 0.36 & 0.67 & 0.21 & 0.82 & 1.00 \\
\hline
\end{tabular}

(b) FSVAR estimated counterfactuals for $1984-2002$ using common shock variances from 1960 - 1983

\begin{tabular}{|l|c|c|c|c|c|c|c|}
\hline & Canada & France & Germany & Italy & Japan & UK & US \\
\hline Canada & 1.00 &. &. &. &. &. &. \\
\hline France & 0.82 & 1.00 &. &. &. &. &. \\
\hline Germany & 0.53 & 0.79 & 1.00 &. &. &. &. \\
\hline Italy & 0.80 & 0.96 & 0.78 & 1.00 &. &. &. \\
\hline Japan & 0.34 & 0.29 & 0.37 & 0.32 & 1.00 &. &. \\
\hline UK & 0.93 & 0.83 & 0.54 & 0.83 & 0.32 & 1.00 &. \\
\hline US & 0.95 & 0.89 & 0.59 & 0.86 & 0.35 & 0.94 & 1.00 \\
\hline
\end{tabular}

Notes: Entries are square root of the average coherence at business cycle frequencies, as defined in (8), computed using the FSVAR described in Section 4. The factual (panel (a)) and counterfactual (panel (b)) scenarios are the same as in Table 9. 
Figure 1. Four-quarter growth rates of GDP
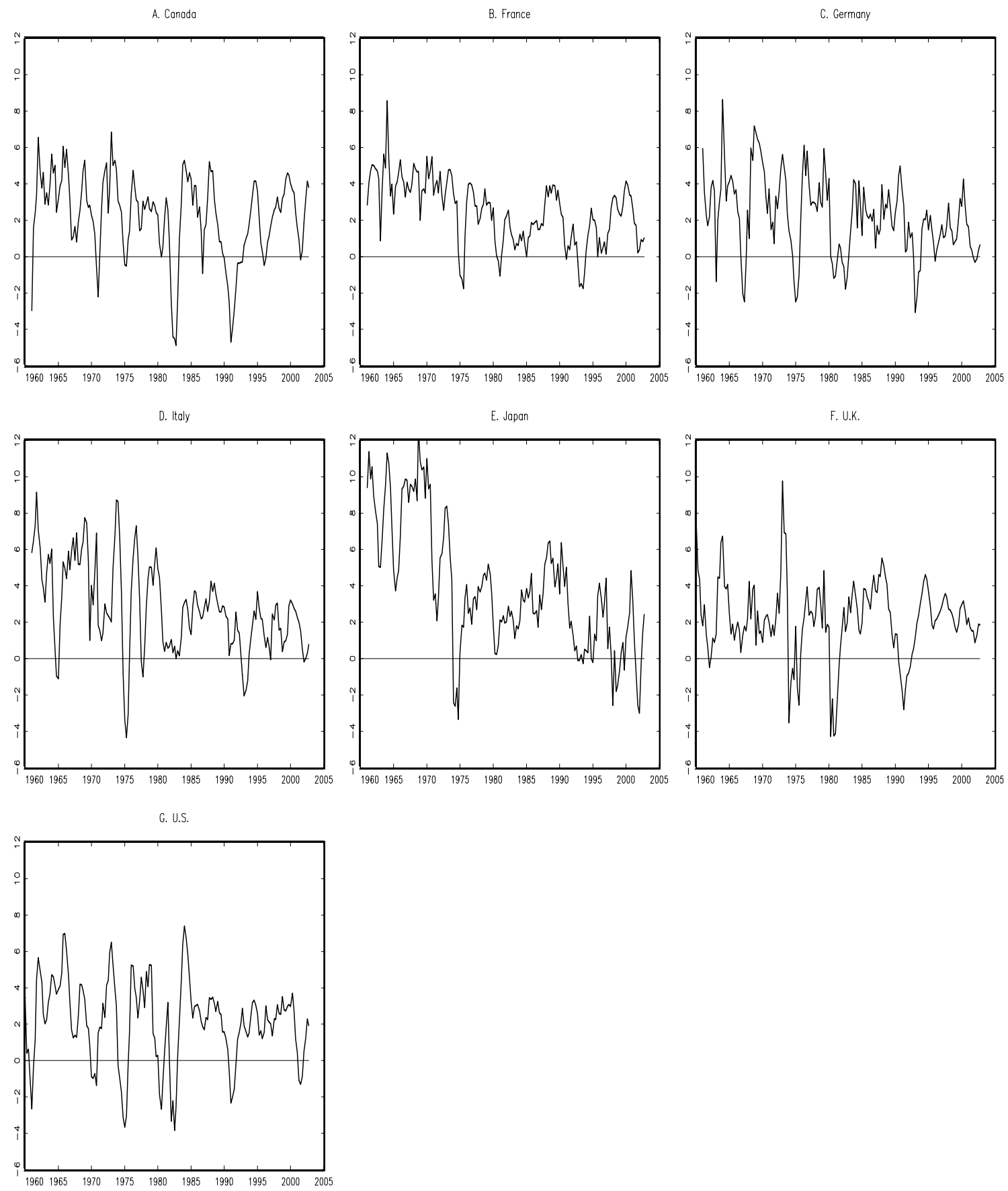
Figure 2. Detrended four-quarter GDP growth:

individual countries (solid lines) and G7 aggregate (dashed line)
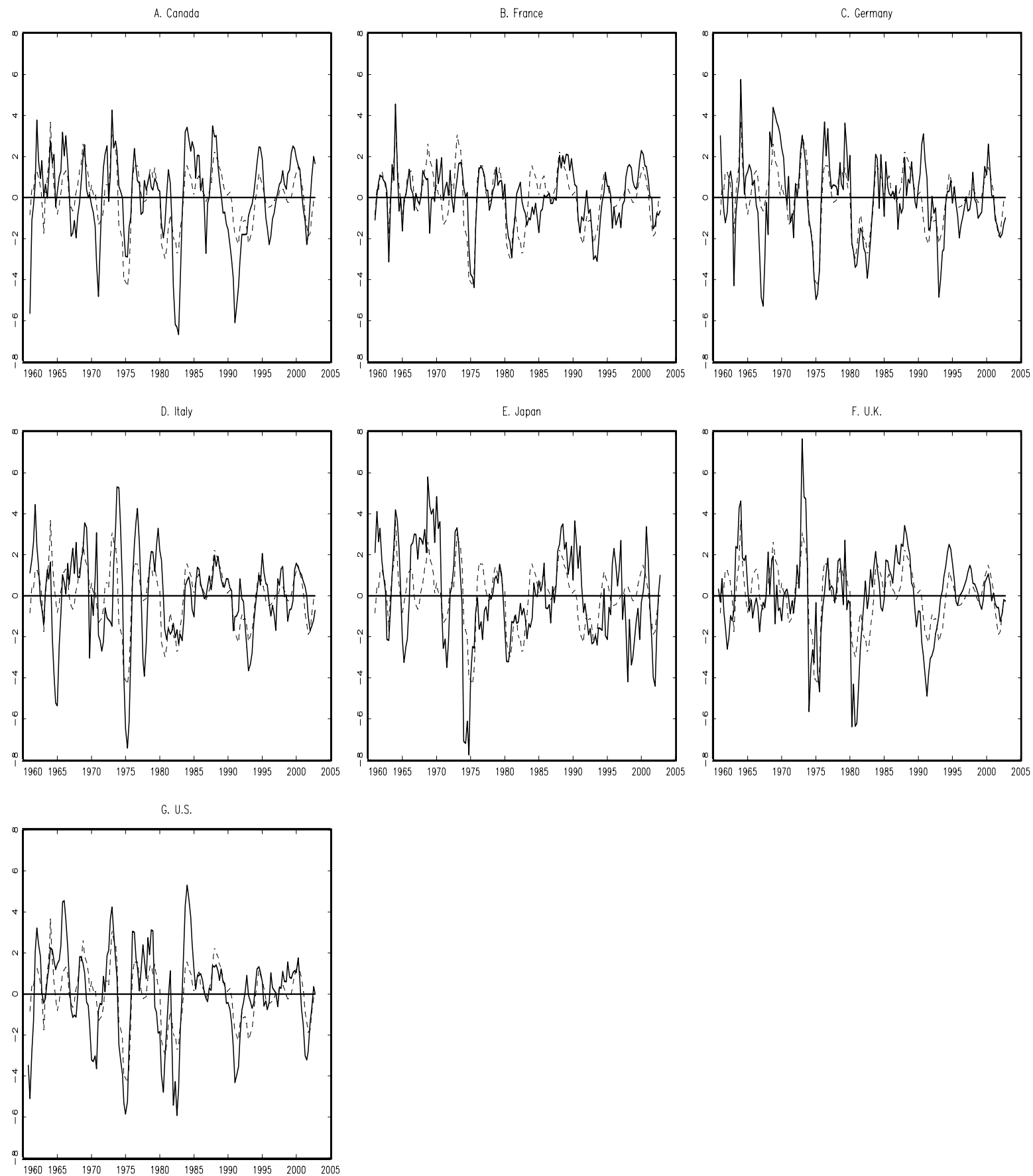
Figure 3. Band-pass GDP growth:

individual countries (solid lines) and G7 aggregate (dashed line)
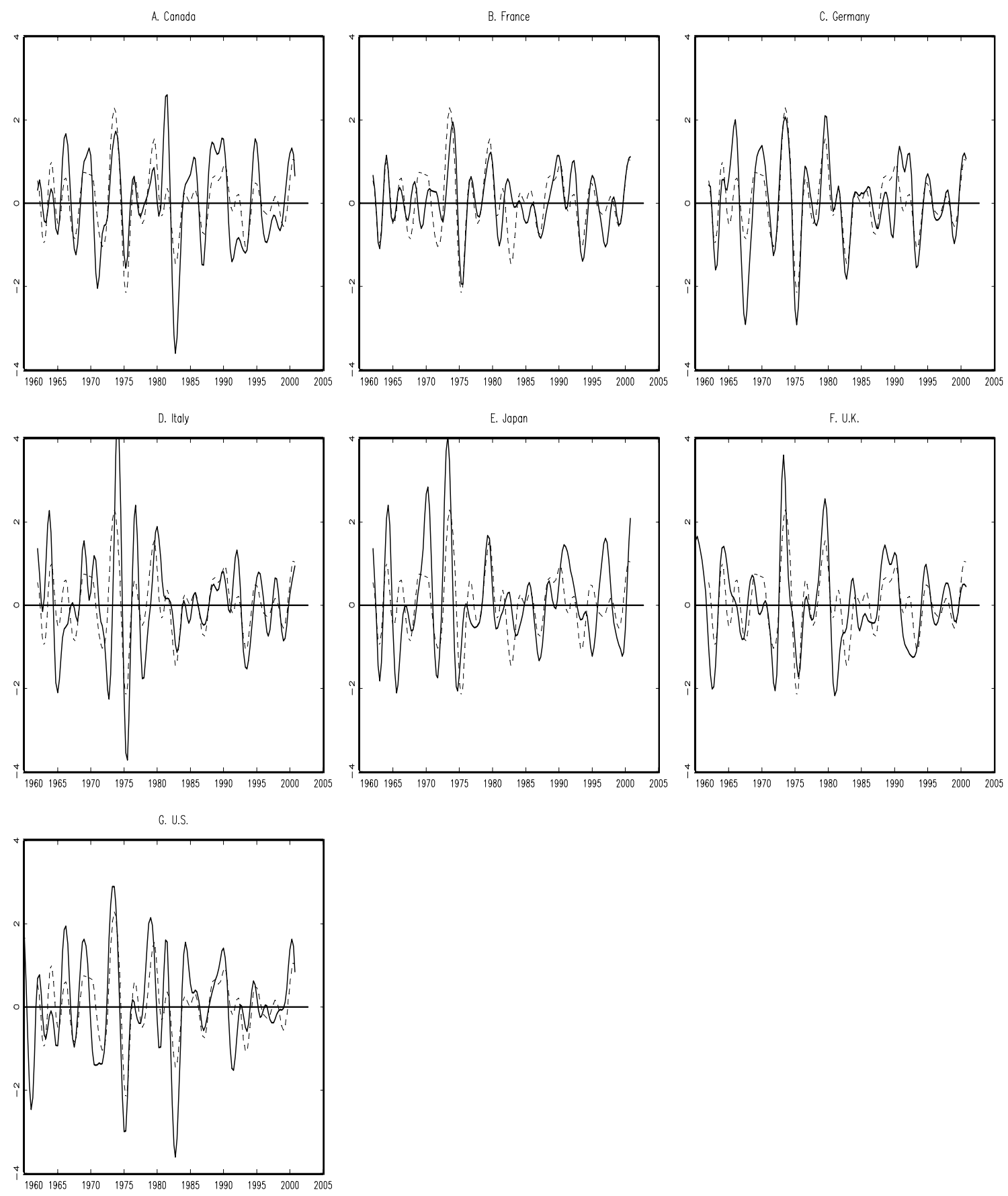
Figure 4. Estimated instantaneous standard deviation of 4-quarter GDP growth
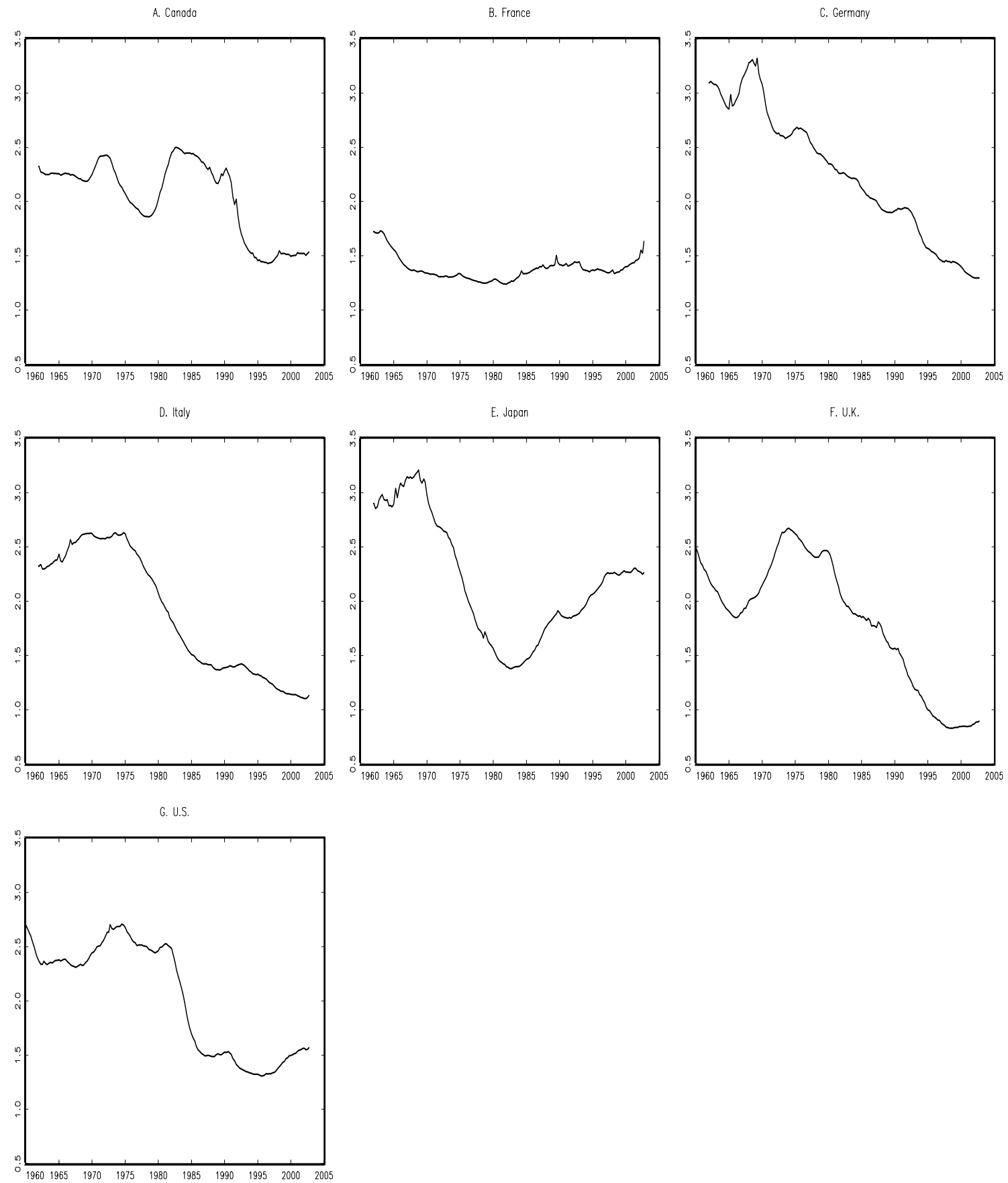
Figure 5. Estimated instantaneous standard deviation of BP GDP
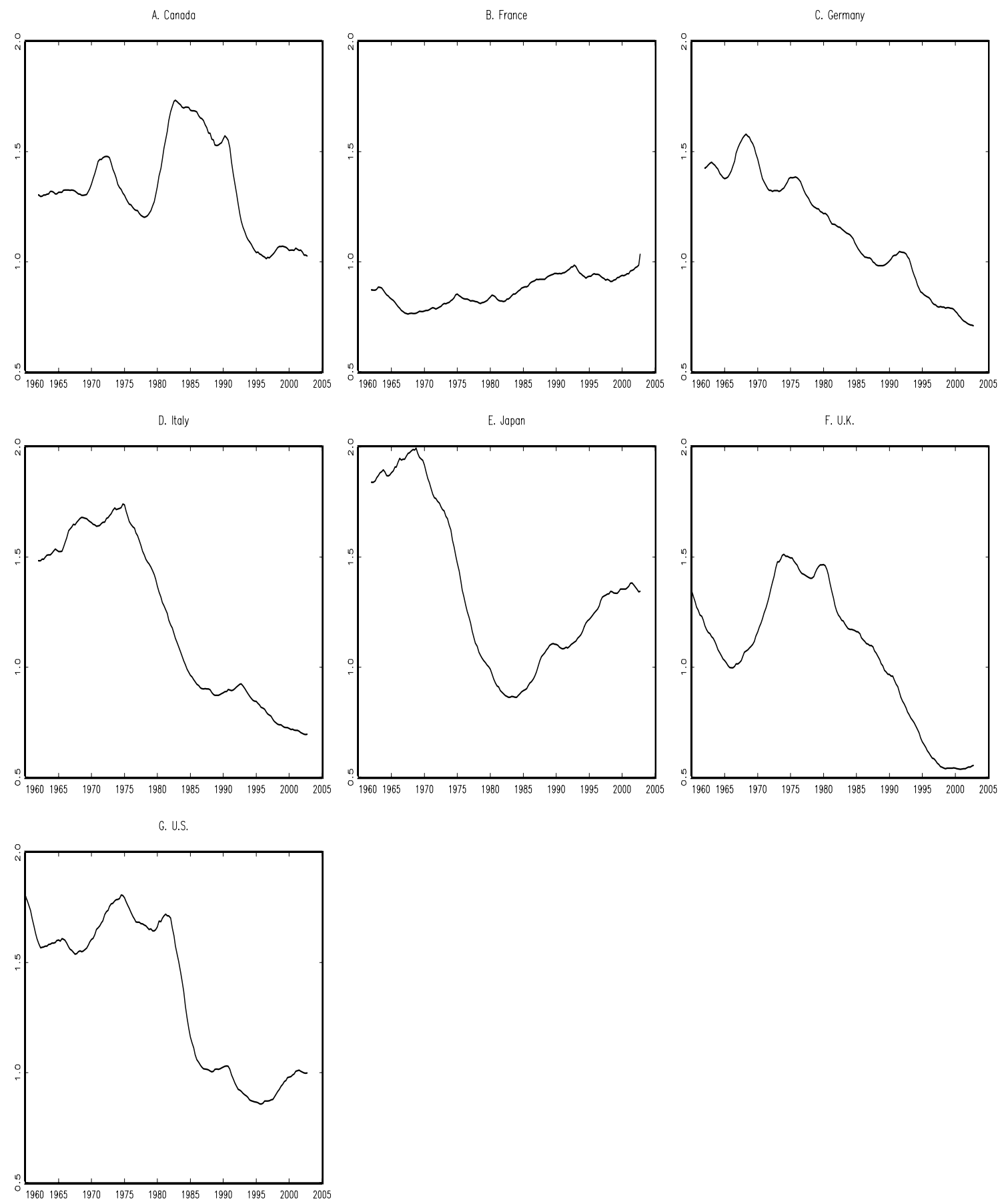
Figure 6a. Rolling autoregressions: sum of AR coefficients $(\hat{\alpha}(1))$
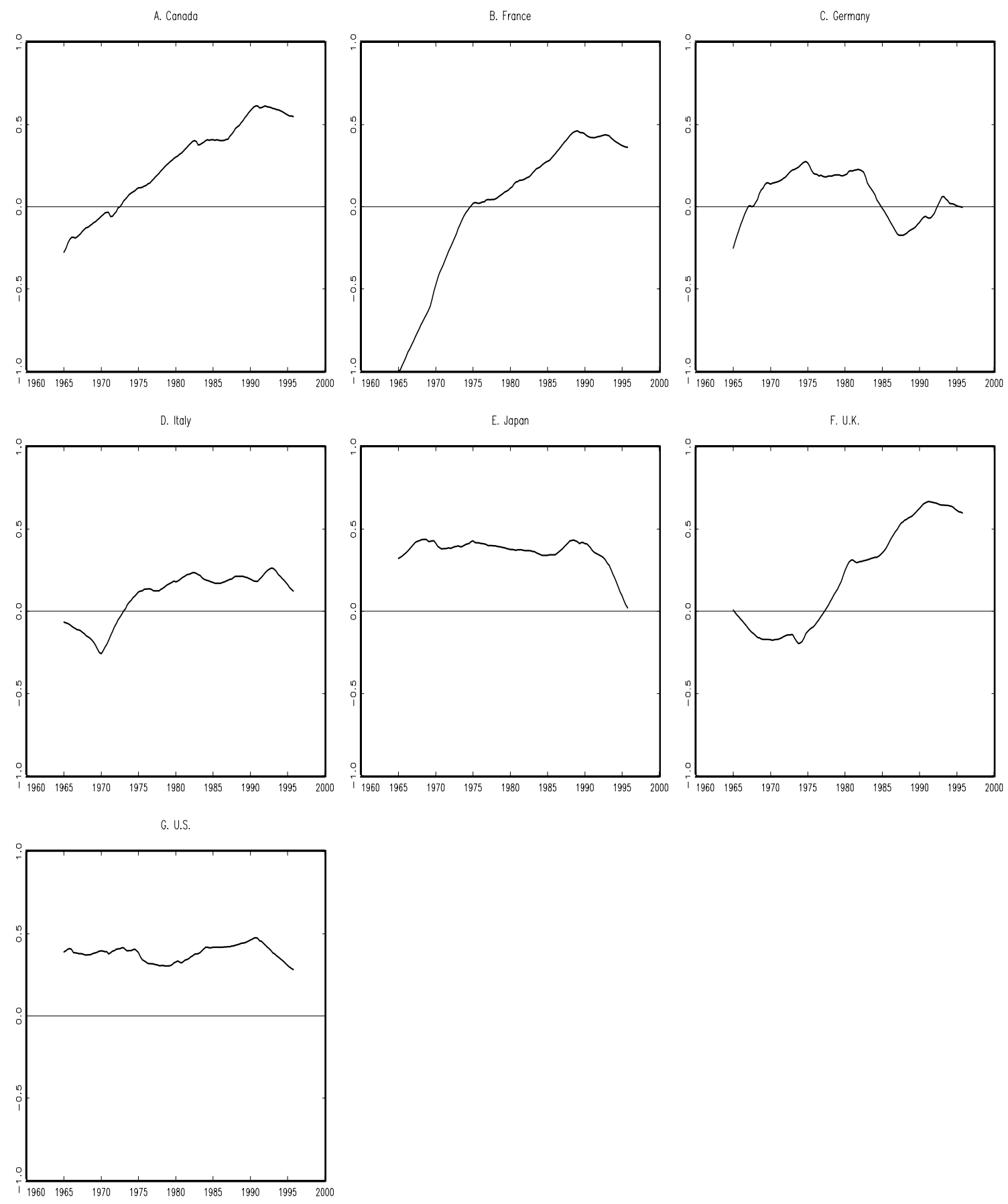
Figure 6b. Rolling autoregressions: innovation standard error $\left(\hat{\sigma}_{\varepsilon}\right)$
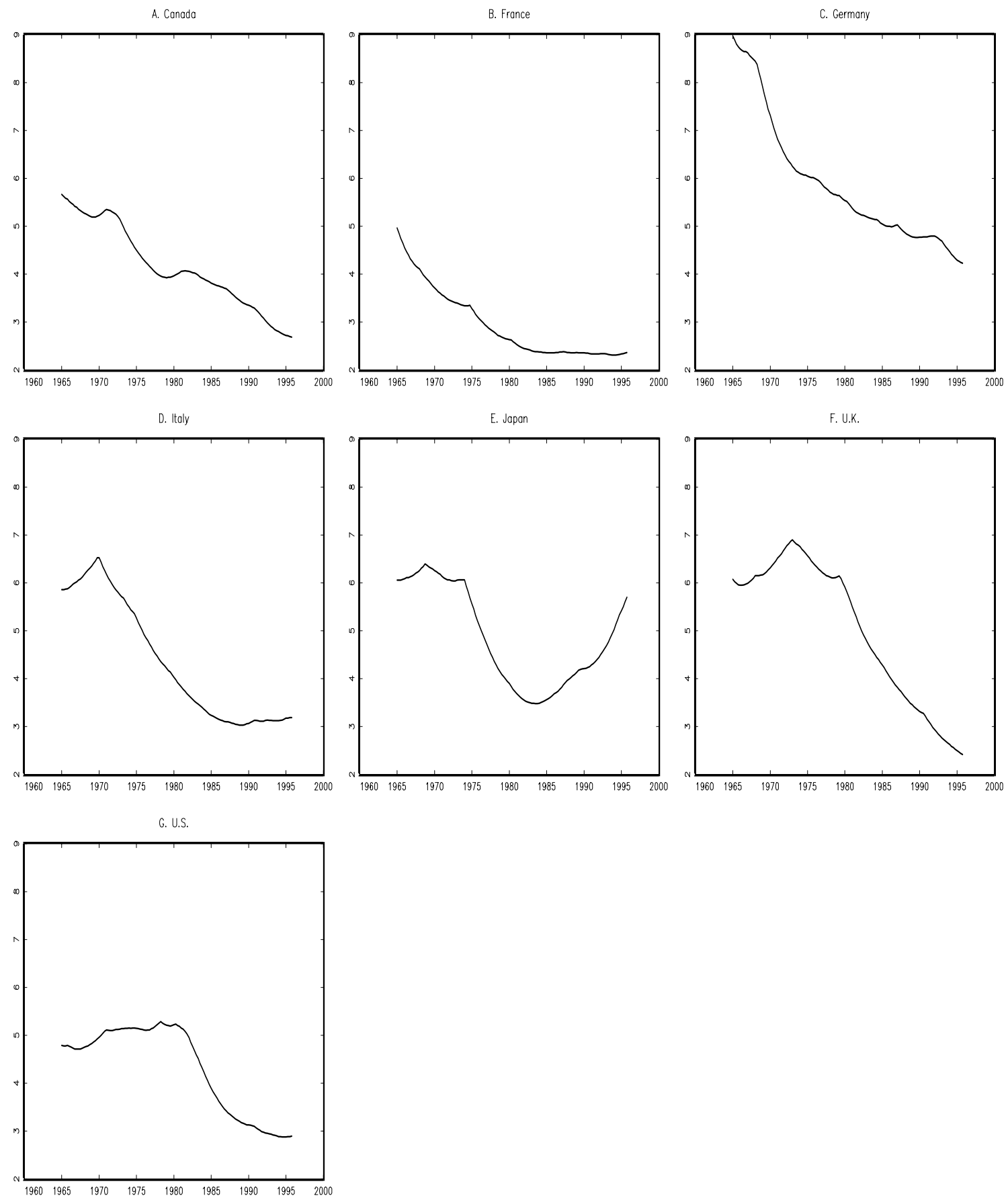
Figure 7. Band-pass GDP growth:

rolling correlation with US (solid line) and Germany (dashed line)
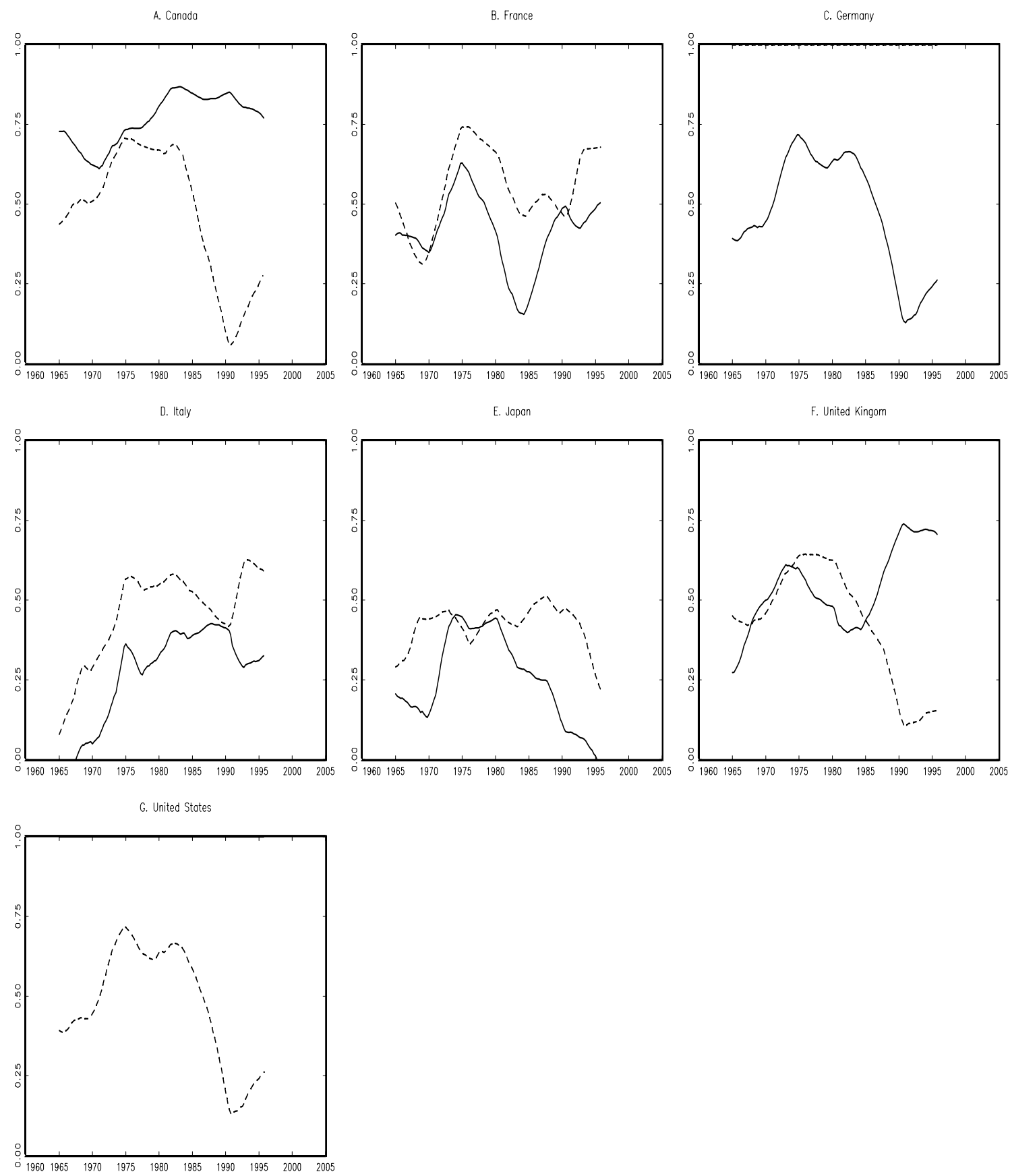
Figure 8. Rolling FSVAR Variance decomposition of BP-filtered GDP growth:

International shocks (lower); international shocks + spillovers (middle); and total (top)
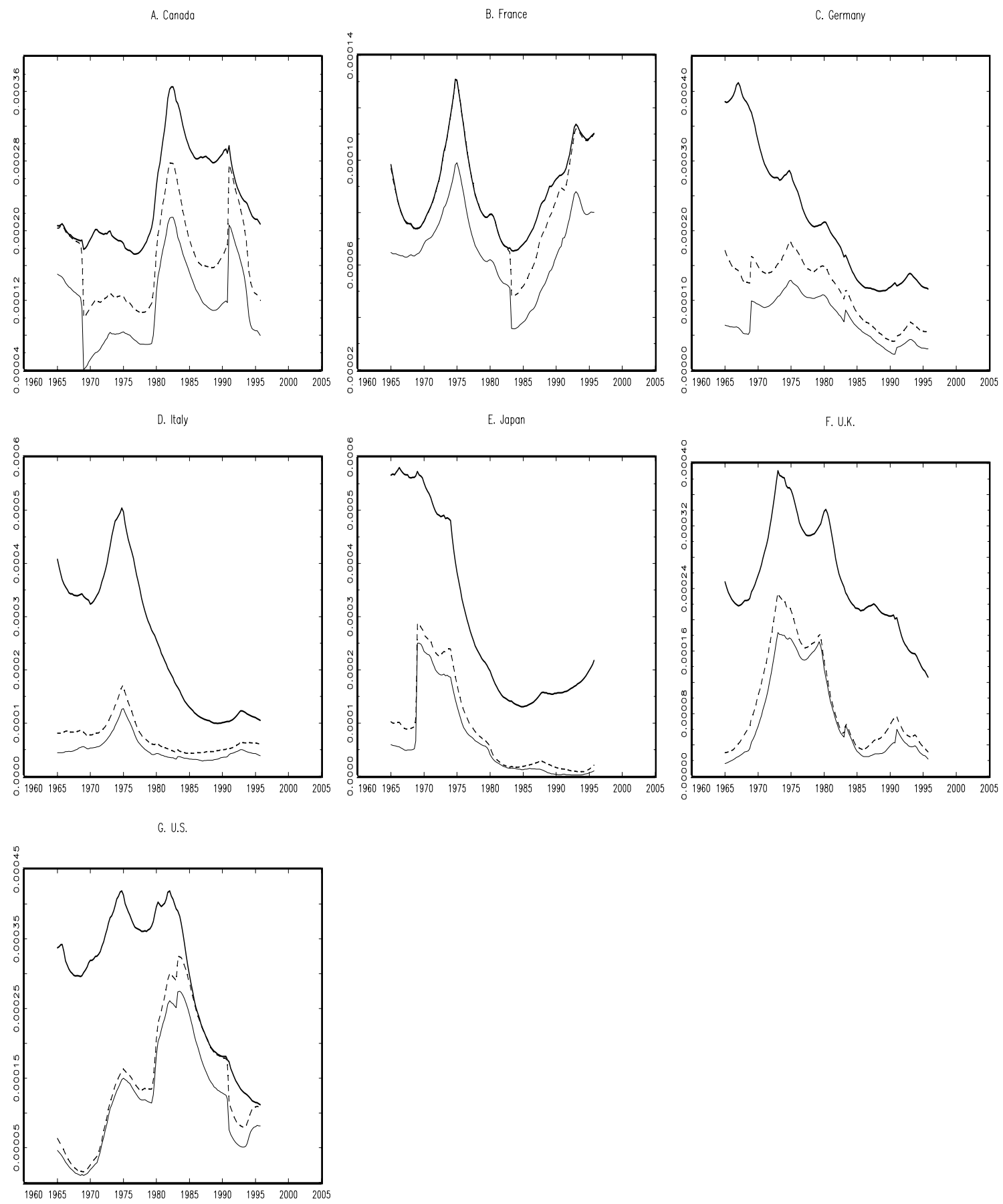
Figure 9a. Cumulative impulse response function: first common factor in 1960 - 198 (solid line) and 1984 - 2002 (dashed line)
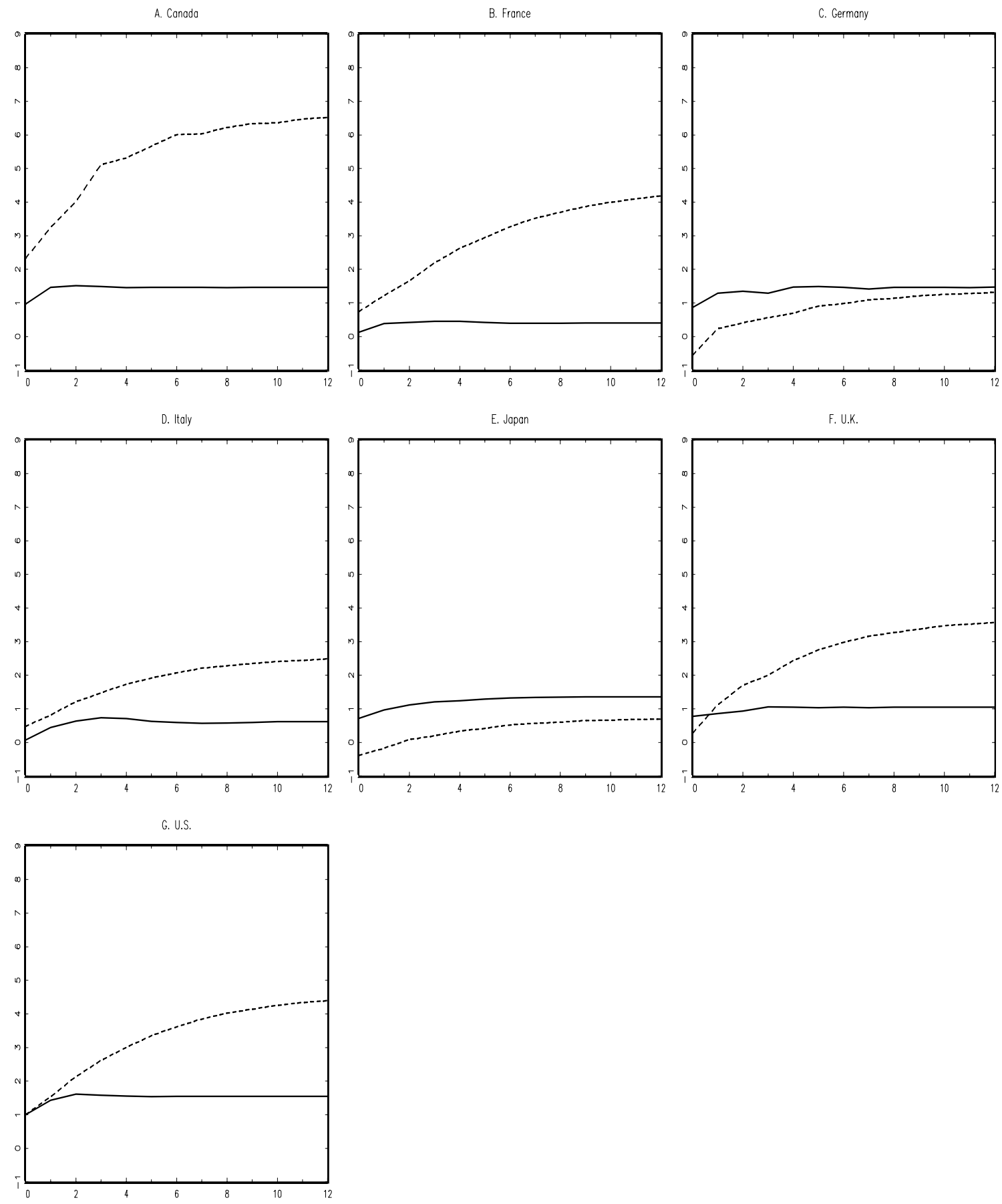
Figure 9b. Cumulative impulse response function: second common factor in 1960 - 198 (solid line) and $1984-2002$ (dashed line)
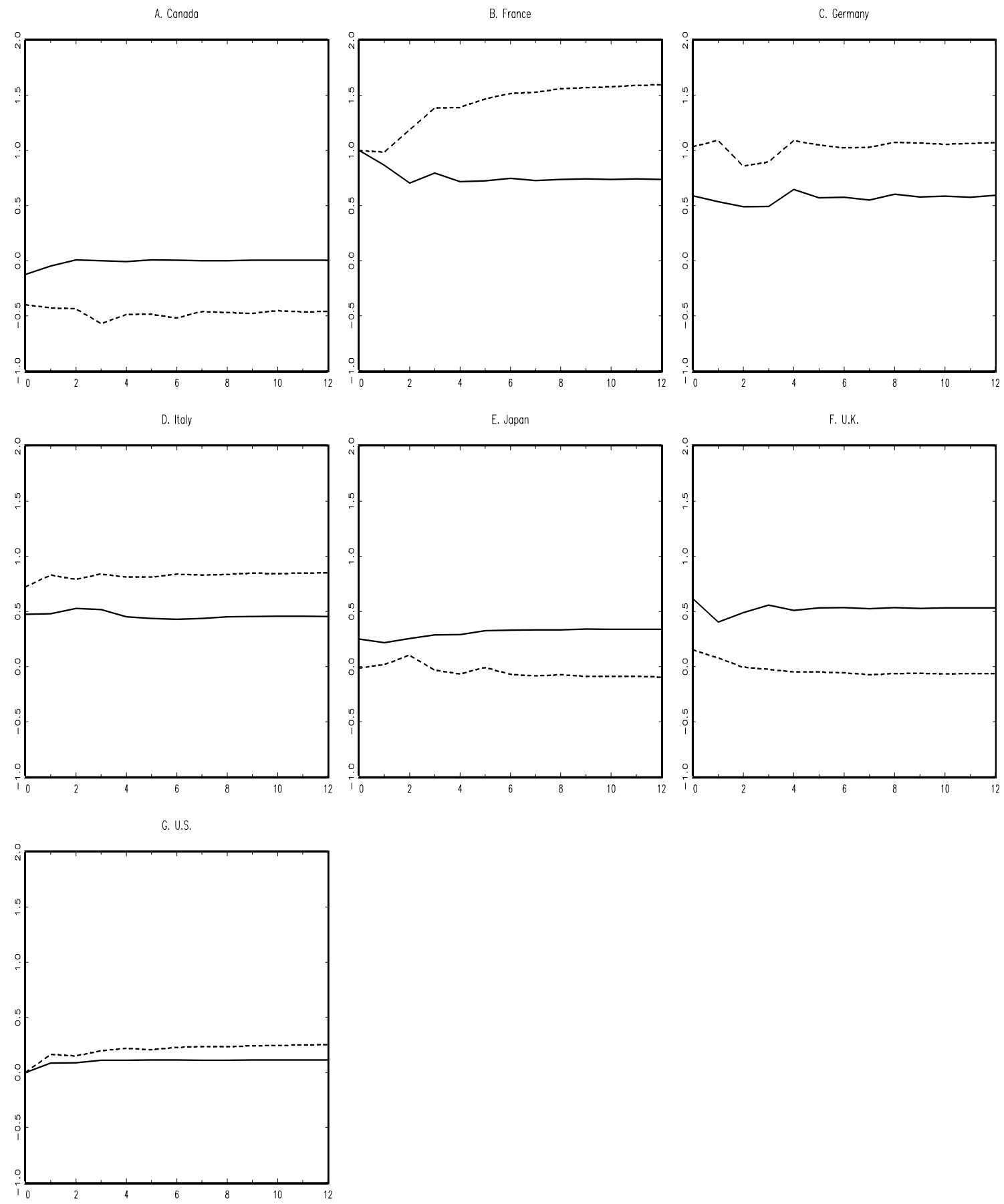